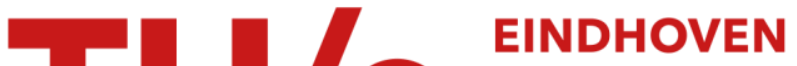 UNIVERSITY OF TECHNOLOGY
}

\section{Self-Assembly of Elastin-like Polypeptide Brushes on Silica Surfaces and Nanoparticles}

Citation for published version (APA):

Alvisi, N., Gutiérrez-Mejía, F. A., Lokker, M., Lin, Y. T., de Jong, A. M., van Delft, F., \& de Vries, R. (2021). SelfAssembly of Elastin-like Polypeptide Brushes on Silica Surfaces and Nanoparticles. Biomacromolecules, 22(5), 1966-1979. https://doi.org/10.1021/acs.biomac.1c00067

DOI:

10.1021/acs.biomac.1c00067

Document status and date:

Published: 01/05/2021

\section{Document Version:}

Publisher's PDF, also known as Version of Record (includes final page, issue and volume numbers)

\section{Please check the document version of this publication:}

- A submitted manuscript is the version of the article upon submission and before peer-review. There can be important differences between the submitted version and the official published version of record. People interested in the research are advised to contact the author for the final version of the publication, or visit the $\mathrm{DOI}$ to the publisher's website.

- The final author version and the galley proof are versions of the publication after peer review.

- The final published version features the final layout of the paper including the volume, issue and page numbers.

Link to publication

\section{General rights}

Copyright and moral rights for the publications made accessible in the public portal are retained by the authors and/or other copyright owners and it is a condition of accessing publications that users recognise and abide by the legal requirements associated with these rights.

- Users may download and print one copy of any publication from the public portal for the purpose of private study or research.

- You may not further distribute the material or use it for any profit-making activity or commercial gain

- You may freely distribute the URL identifying the publication in the public portal.

If the publication is distributed under the terms of Article 25fa of the Dutch Copyright Act, indicated by the "Taverne" license above, please follow below link for the End User Agreement:

www.tue.nl/taverne

Take down policy

If you believe that this document breaches copyright please contact us at:

openaccess@tue.nl

providing details and we will investigate your claim. 


\section{Self-Assembly of Elastin-like Polypeptide Brushes on Silica Surfaces and Nanoparticles}

Nicolò Alvisi, Fabiola A. Gutiérrez-Mejía, Meike Lokker, Yu-Ting Lin, Arthur M. de Jong, Floris van Delft, and Renko de Vries*

Cite This: Biomacromolecules 2021, 22, 1966-1979

Read Online

\section{ACCESS I}

山ll Metrics \& More

Article Recommendations

Supporting Information

ABSTRACT: Control over the placement and activity of biomolecules on solid surfaces is a key challenge in bionanotechnology. While covalent approaches excel in performance, physical attachment approaches excel in ease of processing, which is equally important in many applications. We show how the precision of recombinant protein engineering can be harnessed to design and produce proteinbased diblock polymers with a silica-binding and highly hydrophilic elastin-like domain that self-assembles on silica surfaces and nanoparticles to form stable polypeptide brushes that can be used as a scaffold for later biofunctionalization. From atomic force microscopy-based single-molecule force spectroscopy, we find

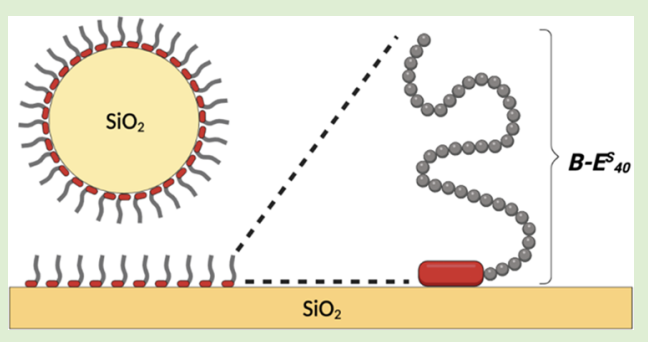
that individual silica-binding peptides have high unbinding rates. Nevertheless, from quartz crystal microbalance measurements, we find that the self-assembled polypeptide brushes cannot easily be rinsed off. From atomic force microscopy imaging and bulk dynamic light scattering, we find that the binding to silica induces fibrillar self-assembly of the peptides. Hence, we conclude that the unexpected stability of these self-assembled polypeptide brushes is at least in part due to peptide-peptide interactions of the silicabinding blocks at the silica surface.

\section{INTRODUCTION}

A key aspect of bionanotechnology is control of placement and activity of biomolecules on solid surfaces. For example, biofunctionalization of solid surfaces is crucial in biosensing and for implanted biomaterials. ${ }^{1}$ In the simplest approaches, biomolecules are either directly immobilized on surfaces through often nonspecific covalent bonds or physically adsorbed. ${ }^{2,3}$ Covalent coupling makes for stronger immobilization since bonds are typically irreversible. On the other hand, physical adsorption generates bonds to the surface that are typically reversible, but the process is much simpler.

In biosensing, an important example is the surface attachment of antibodies used to detect antigens. Direct nonspecific covalent immobilization of antibodies on surfaces may lead to significant loss of antibody activity, especially at high surface densities. ${ }^{4}$ This is supposedly caused by (permanent) misorientation of the antibodies leading to loss of accessibility of the antibody-binding region for the antigens and by (partial) denaturation of the antibodies caused by the direct contact with the surface (Figure 1a). The same mechanisms are operative when antibodies are directly physically adsorbed on surfaces (Figure $1 \mathrm{~b}$ ). One solution to avoid misorientation or denaturation is to indirectly attach antibodies (or other bioactive molecules) to the surface via polymer brushes (Figure 1c), which has the additional advantage that the performance of diagnostic devices can be improved using antifouling polymers. ${ }^{5}$ The technology for the synthesis and subsequent functionalization of antifouling polymer brushes on solid substrates has reached a sophisticated level. ${ }^{6,7}$ However, the required procedures for low-cost, bulk applications are still too complex and hence too expensive. Therefore, there is continued interest in the development of technologies for the generation of stable polymer brushes via simple adsorption.

The most notable examples of noncovalently immobilized polymer brushes are PEG [poly(ethylene glycol)] copolymers such as PEG- $g$-PLL (poly L-lysine) and PEG- $g$-PEI (polyethylene imine). ${ }^{8}$ These have a so-called "bottle-brush" architecture, consisting of a polycationic main chain (PLL or PEI) to which short PEG side chains are grafted. The polycationic main chain adsorbs onto many relevant surfaces, the PEG side chains extend perpendicular from the polycationic main chain, thereby forming a brush. PEG is widely used as an antifouling material, ${ }^{6}$ while bioactive molecules can be readily attached to the PEG side chains using chemical procedures ${ }^{9-11}$ (Figure 1d).

A complementary approach to synthetic polymers is the use of recombinant or synthetic polypeptides. Polypeptides offer the advantage of precise control of polymer chemistry, ${ }^{12}$

Received: January 19, 2021

Revised: March 23, 2021

Published: April 19, 2021 


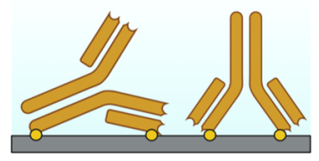

d)

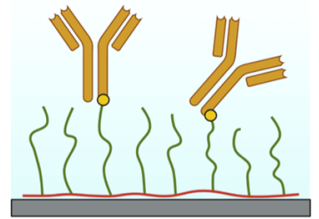

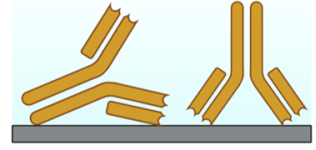

e)

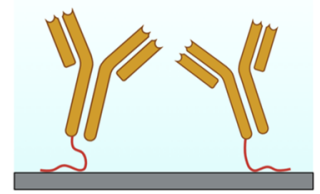

c)

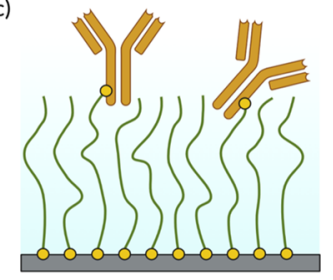

f)

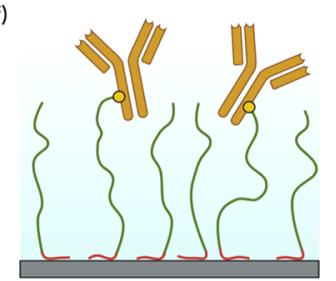

Figure 1. Biomolecule immobilization strategies illustrated for the case of antibodies. (a) Direct covalent attachment. (b) Direct physical adsorption. (c) Attachment to a covalently anchored polymer brush. (d) Attachment to a physically anchored PLL-g-PEG brush. (e) Physical immobilization through an SBP immobilization tag. (f) Physical immobilization through an SBP immobilization tag and antifouling polypeptide linker.

including the conjugation of bioactive molecules such as antibodies, and the possibility to directly include other functional peptide or protein blocks in the design. ${ }^{13}$ Another advantage is the possibility to exploit many extensively studied solid-binding peptides (SBPs) as binding modules for specific surfaces. SBPs are short amino acid sequences that interact noncovalently with solid surfaces, with affinities in the microto nanomolar range ${ }^{14}$ and have been widely employed as immobilization tags for the direct immobilization of proteins on various surfaces (Figure 1e). ${ }^{15-17}$ However, as emphasized before, attachment to an antifouling polymer brush is preferred to prevent loss of activity of sensitive biomolecules such as antibodies.

There is some precedent for the use of SBPs as part of genetically engineered polypeptide designs. For example, sequences based on spider silk have been fused to sequences for silica-binding domains in order to synthesize biomimetic coatings for nanoparticles. ${ }^{18}$ The chimeric silk proteins form $\beta$ sheet-rich fibers on silica surfaces. In a similar strategy, Li et al. have used silica-binding domains to immobilize micelles of elastin-like polypeptides (ELPs) on silica nanoparticles and surfaces. ${ }^{19}$

Immobilization using a diblock polypeptide with an SBP and an inert hydrophilic domain such as a hydrophilic ELP (Figure 1f) is another promising option. This design has recently been explored by Li et al. ${ }^{20}$ for the immobilization of cells on gold surfaces. Here, we wish to explore a similar diblock design for coating another widely occurring type of surface, viz., silica surfaces.

Following $\mathrm{Li}$ et al., ${ }^{20}$ for the inert and antifouling polypeptide blocks, we use ELPs. ELPs are based on sequence motifs from human tropoelastin, ${ }^{21}$ characterized by the pentapeptide motif $\boldsymbol{E}^{X}=$ VPGXG, where $X$ is any amino acid except proline, and have been well-characterized. ${ }^{22}$ Indeed, ELPs have found applications in biosensing, ${ }^{23}$ tissue engineering, ${ }^{24}$ nanoparticle coatings, ${ }^{25}$ drug-delivery systems, ${ }^{26}$ biomineralization studies, ${ }^{27}$ immunoassays, ${ }^{28}$ and molecular switches. ${ }^{29}$ To obtain inert and hydrophilic polypeptide brushes, we choose serine as a guest residue in the ELPs, $\mathrm{X}$ $=\mathrm{S}$.

Some of us have previously developed a diblock polypeptide $C-B^{K 12}$ consisting of an oligolysine block $B^{K 12}=K_{12}$ and a random coil hydrophilic block with a collagen-like sequence, $\boldsymbol{C}$ $=(\text { GXaaYaa })_{132}$. The $\boldsymbol{C}-\boldsymbol{B}^{\boldsymbol{K} 12}$ spontaneously assembles on DNA to form a dense brush. ${ }^{30}$ The same diblock polypeptide also assembles into dense hydrophilic brushes on the surface of nanodiamonds, providing the nanodiamonds with colloidal stability and promoting their uptake by cells. ${ }^{31}$

Building on our previous experience with the $C-B^{K 12}$ diblock, the basic design that we study here is again a simple diblock. We explore $\boldsymbol{B}-\boldsymbol{E}^{\boldsymbol{S}}{ }_{40}$ diblocks, where $\boldsymbol{E}^{\boldsymbol{S}}=$ (VPGSG) and $\boldsymbol{B}$ is a series of silica-binding peptide blocks. First, we characterized in detail the silica-binding properties of the $\boldsymbol{B}$ domains, using quartz crystal microbalance (QCM), atomic force microscopy (AFM), and single-molecule force spectroscopy (SMFS). ${ }^{32-35} \mathrm{Next}$, we demonstrate that the $\boldsymbol{B}-\boldsymbol{E}_{40}^{S}$ diblocks form dense polymer brushes on silica surfaces and show that the diblocks stabilize silica nanoparticles. We also explore interactions of coated silica nanoparticles with coated silica surfaces using a single-particle surface mobility assay. We find that even prolonged rinsing, except with very high ionic strength buffers, does not displace the diblocks from silica surfaces, which we attribute to strong peptide-peptide interactions of the SBPs on the silica surface, in addition to their inherent affinity to silica surfaces.

\section{MATERIALS AND METHODS}

"Scan-Asyst air" AFM tips were purchased from Bruker, and the Maleimide-PEG-NHS molecule was purchased from Polypure. QCMD sensors were purchased from Biolin Scientific. A number of peptides were custom-ordered from PepScan (see Table 1), the

Table 1. Purity and Molecular Weight of Synthetic Peptides

\begin{tabular}{llcc}
\multicolumn{1}{c}{ name } & \multicolumn{1}{c}{ sequence } & MW $(\mathrm{Da})$ & purity $(\%)$ \\
$\boldsymbol{B}^{R 14}$ & $\mathrm{R}_{14}$ & 2151.6 & $>96$ \\
$\boldsymbol{B}^{R 13}-\mathrm{Cys}$ & $\mathrm{R}_{13} \mathrm{C}$ & 2204.7 & $>99$ \\
$\boldsymbol{B}^{R T}$ & $(\mathrm{RTHRK})_{4}$ & 2732.3 & $>98$ \\
$\boldsymbol{B}^{R T}-\mathrm{Cys}$ & $(\mathrm{RTHRK})_{4} \mathrm{C}$ & 2835.5 & $>92$ \\
$\boldsymbol{B}^{R Q}$ & $(\mathrm{RQSSRGR})_{2}$ & 1672.9 & $>92$ \\
$\boldsymbol{B}^{R Q}-\mathrm{Cys}$ & $(\mathrm{RQSSRGR})_{2} \mathrm{C}$ & 1776.1 & $>98$ \\
$\boldsymbol{E}^{S}{ }_{3}$ & $(\mathrm{VPGSG})_{3}$ & 1210.3 & $>99$ \\
$\boldsymbol{E}^{S}{ }_{3}-\mathrm{Cys}$ & $(\mathrm{VPGSG})_{3} \mathrm{C}$ & 1313.5 & $>98$
\end{tabular}


reported purity is from HPLC analysis, reported mass is the experimental mass from mass spectrometry. Peptides were ionexchanged to $\mathrm{Na}^{+}$counterions by the manufacturer. Poly(L-lysine)grafted poly(ethylene glycol) was purchased from SuSoS (Switzerland) with a grafting ratio of 3.5. The molecular weight of the PLL backbone and PEG side chains was 20 and $2 \mathrm{kDa}$, respectively. All other chemical reagents were purchased from Sigma-Aldrich.

Buffer Preparation. $10 \mathrm{mM}$ phosphate buffer (PB) $\mathrm{pH} 7.4$ with different amounts of added $\mathrm{NaCl}$ is used throughout. Buffer solutions were filtered and degassed before use.

Quartz Crystal Microbalance with Dissipation Monitoring (QCM-D). A Q-Sense E4 (Biolin, Sweden) QCM-D instrument was used to quantify peptide and polypeptide binding to silica. QCM sensors coated with $\mathrm{SiO}_{2}$ were obtained from the instrument manufacturer and cleaned according to instructions of the manufacturer. Prior to measurements, the instrument was equilibrated with a starting buffer ( $\mathrm{PB}$ with added $\mathrm{NaCl}$ as indicated) for at least $20 \mathrm{~min}$ at a flow rate of $50 \mu \mathrm{L} / \mathrm{min}$. Analysis of QCMD data was performed using QSense software (Biolin). For some measurements, a linear filter was applied to correct for a small amount of baseline drift. Experimental observables are the changes in resonance frequency $(\Delta f)$ and energy dissipation $(D)$. If energy dissipation is small enough, the adsorbed mass $\Delta m$ per unit area is calculated from the change in resonance frequency through the Sauerbrey equation

$$
\Delta f=-C \frac{\Delta m}{n}
$$

The oscillation frequency is an (odd) multiple $(n=1,3,5, \ldots)$ of the crystal resonance frequency $(5 \mathrm{MHz})$. The numerical prefactor (for a $5 \mathrm{MHz}$ crystal, per unit area of crystal surface $)$ is $C=17.7 \mathrm{ng} /\left(\mathrm{cm}^{2}\right.$. $\mathrm{Hz}$ ). The active area of the crystal was $0.2 \mathrm{~cm}^{2}$. Adsorbed masses per unit area $\Gamma$ obtained from the Sauerbrey equation versus the bulk concentration $C$ were fitted using an effective Langmuir adsorption isotherm

$$
\Gamma=\frac{K_{\mathrm{d}, \mathrm{app}} c}{1+K_{\mathrm{d}, \mathrm{app}} c} \Gamma_{\max }
$$

where $\Gamma_{\max }$ is the limiting adsorption, at high concentrations, and $K_{\mathrm{d}, \text { app }}$ is an apparent dissociation constant.

AFM Tip Functionalization. We followed previously published protocols for functionalization of AFM tips for single-molecule force measurements. ${ }^{36}$ AFM tips (Bruker) were cleaned with chloroform. Amino activation was performed by immersing the AFM tips in $30 \mu \mathrm{L}$ of APTES and $10 \mu \mathrm{L}$ of triethylamine, in a closed chamber under an argon atmosphere, for $2 \mathrm{~h}$. Next, tips were cleaned again with chloroform and nitrogen gas and $1 \mathrm{mg}$ of a maleimide-PEG-NHS linker was dissolved in $0.5 \mathrm{~mL}$ of chloroform and $30 \mu \mathrm{L}$ of triethylamine. AFM cantilevers were then soaked in this solution (in a small Teflon beaker) for $3 \mathrm{~h}$. Finally, tips were washed three times with chloroform. Peptides $B^{R 13} C y s, B^{R T} C y s, B^{R Q} C y s$, and $E_{3}^{S} C y s$ were covalently attached to maleimide groups of the PEG linkers attached to the AFM tips via thiol bonds. To this end, a solution was prepared of $100 \mu \mathrm{L}$ of peptide $(100 \mu \mathrm{M}), 2 \mu \mathrm{L}$ of EDTA $(100 \mathrm{mM}, \mathrm{pH} 7.5), 5$ $\mu \mathrm{L}$ of HEPES ( $1 \mathrm{M} \mathrm{pH} 7.5), 2 \mu \mathrm{L}$ of TCEP $(100 \mathrm{mM})$, and $2 \mu \mathrm{L}$ of HEPES ( $1 \mathrm{M}, \mathrm{pH}$ 9.6). Tips were immersed in the abovementioned solution for $4 \mathrm{~h}$. Tips were washed with $\mathrm{PB}$ and stored at $4{ }^{\circ} \mathrm{C}$ in $\mathrm{PB}$ for not more than 2 weeks before use.

AFM Imaging in Air. Atomically flat silica surfaces were obtained using silicon wafers (Siltronic AG) with a $2-3 \mathrm{~nm}$ oxide layer due to natural oxidation with oxygen in air. Silica surfaces were cleaned with Milli-Q water and ethanol and plasma-cleaned for $5 \mathrm{~min}$. For AFM imaging, peptide solutions, at concentrations as indicated, were filtered with a $10 \mathrm{kDa}$ centrifugal filter and sonicated for $30 \mathrm{~min}$ to ensure that no peptide aggregates were present prior to imaging. Next, cleaned silica surfaces were immersed in $100 \mu \mathrm{L}$ of peptide solution for $1 \mathrm{~h}$. Silica samples were gently rinsed with Milli-Q water and carefully dried with nitrogen. Samples were imaged with a Multimode Bruker AFM (Bruker, California) using the automatic ScanAsyst imaging mode. ScanAsyst air tips were used with a nominal radius $<10$ nm.

Dynamic Light Scattering. For dynamic light scattering (DLS), a ZS-Nano (Malvern, UK) instrument was used, employing smallvolume $(20 \mu \mathrm{L})$ quartz cuvettes. Light scattering was measured at a scattering angle of $173^{\circ}$, at room temperature, $T=20{ }^{\circ} \mathrm{C}$. Hydrodynamic sizes reported are the average of three measurements, obtained using the Zetasizer software version 7.13 (Malvern, UK). For DLS on peptide solutions, peptide solutions were filtered using a $10 \mathrm{kDa}$ centrifugal filter and sonicated for $30 \mathrm{~min}$ to ensure that no peptide aggregates were present prior to the measurement. For each peptide sample, continuous (time-dependent) measurements were performed, and each reported hydrodynamic size is the average of three measurements (with duration of the measurement being controlled using the instrument). For measurements on silica nanoparticles coated with polypeptides, the polypeptide solution and the silica nanoparticles were sonicated for $15 \mathrm{~min}$. The polypeptide solution was filtered using a $0.22 \mu \mathrm{m}$ filter. Increasing concentrations of polypeptide were incubated with the silica nanoparticles for $10 \mathrm{~min}$. For each sample, continuous measurements were performed, and each reported hydrodynamic size is the average of three measurements, with duration of the measurement being controlled using the instrument.

SMFS Measurements. Silica surfaces were prepared as described for AFM imaging in air. Functionalized tips prepared as described above were used, and experiments were performed in $\mathrm{PB}$ buffer $\mathrm{pH}$ 7.4 at the indicated concentration of $\mathrm{NaCl}$. Single-molecule forceextension measurements, in a liquid flow cell, were performed using a ForceRobot 300 instrument (JPK, Berlin) which allowed to probe a grid of points $(10 \mu \mathrm{m} \times 10 \mu \mathrm{m})$ on the silica surface for multiple times, to give a total of $>2000$ measurements per pulling rate. Pulling rates used here were $12,10,5,2.5,1.25,0.625,0.325$, and $0.165 \mu \mathrm{m} / \mathrm{s}$. A contact time between the tip and the surface of $0.2 \mathrm{~s}$ was set to let the peptides bind the surface. The spring constant and sensitivity of the cantilevers used here were calibrated with the contact-free thermal noise routine from the JPK software. The JPKSPM data analysis software, Excel (Redmond, WA), and Matlab (Natick, MA) were used to analyze the data and classify events. For each force-extension curve, a baseline was subtracted. Peptides studied here consist of no more than 21 amino acids. The PEG linker has an average number of 27 repeat units. Assuming a $0.4 \mathrm{~nm}$ contour length per monomer, we expect forces to vanish at extensions longer than about $20 \mathrm{~nm}$. Data was therefore preclassified using the JPKSPM software, with forcedistance curves for which there was still a significant force at extensions $>20 \mathrm{~nm}$ not being analyzed. The loading rate for each curve was obtained as the slope of the force versus time curves immediately before rupture. To analyze the force extension curves, individual force extension curves were analyzed with a freely jointed chain (FJC) model. ${ }^{37}$ For $M$ parallel chains

$$
L(f)=L_{\mathrm{c}}\left(\operatorname{coth}\left(\frac{F b}{k_{\mathrm{B}} T}\right)-\frac{k_{\mathrm{B}} T}{F b}\right)+N_{\mathrm{s}} \frac{F}{M K_{\mathrm{s}}}
$$

where $F$ is the applied force, $N_{\mathrm{s}}$ is the total number of segments, $k_{\mathrm{B}}$ is the Boltzmann constant, and $T$ is the temperature. The contour length $L_{\mathrm{c}}$ determines the overall range of the force extension curve. The Kuhn length $b=0.7 \mathrm{~nm}$ determines the slope in the low-force regime and the curvature in the mid-force regime, while the segment elasticity $M \cdot K_{\mathrm{s}}$ determines the slope in the high-force regime. Only events were analyzed with a single rupture event. A very small subset showed multiple smaller rupture events, and this subset of events was also not taken into account in the analysis.

The loading rate dependence of the rupture force data was fitted to the Friddle-de Yoreo model. ${ }^{38}$ This model accounts for the expected transition from a near-equilibrium regime with fast rebonding at low loading rates $\left(L_{\mathrm{r}}\right)$, to a regime of rapid irreversible nonequilibrium detachment at high loading rates, described using the Bell-Evans model. The near-equilibrium regime is characterized by an apparent equilibrium rupture force $\left(f_{\mathrm{eq}}\right)$ and the nonequilibrium regime is 
characterized by the unbinding rate $k_{\text {off }}$ and distance to the transition state $x_{\mathrm{t}}$

$$
f=f_{\text {eq }}+\frac{k_{\mathrm{B}} T}{x_{t}} \mathrm{e}^{1 / R\left(f_{\mathrm{eq}}\right)} E_{\mathrm{l}}\left(\frac{1}{R\left(f_{\mathrm{eq}}\right)}\right)
$$

where

$$
R\left(f_{\mathrm{eq}}\right)=\frac{L_{\mathrm{r}} \cdot x_{\mathrm{t}}}{k_{\mathrm{off}}\left(f_{\mathrm{eq}}\right) k_{\mathrm{B}} T}
$$

this is solved using the approximate relation $\mathrm{e}^{z} E_{1}(z) \cong \ln \left(1+\mathrm{e}^{-\gamma / z}\right)$ where $\gamma \approx 0.577$ is Euler's constant. Furthermore, $k_{\mathrm{B}}$ is the Boltzmann constant and $T$ is the absolute temperature.

To calculate the free energy of binding per unit length $\Delta G_{\mathrm{b}}$, we use the Manohar relationship ${ }^{39}$ for pulling polymers away from a surface, where $\Delta G_{\mathrm{b}}=\gamma_{\mathrm{adh}} l_{\text {mono }}$ and $l_{\text {mono }}$ is the length of the monomer (for which we take $l_{\text {mono }}=0.35 \mathrm{~nm}$ ). The tension $\gamma_{\text {adh }}$ is

$$
\gamma_{\mathrm{adh}}=\frac{k_{\mathrm{B}} T}{b} \ln \left(\frac{4 \pi \sinh \left(\frac{f_{\mathrm{eq}} b}{k_{\mathrm{B}} T}\right)}{\frac{f_{\mathrm{eq}} b}{k_{\mathrm{B}} T}}\right)
$$

where $b$ is the Kuhn length, for which we take $b \approx 0.7 \mathrm{~nm}$. The free energy is expressed in thermal energies $k_{\mathrm{B}} T$, where $T=298 \mathrm{~K}$ is the temperature of the experiment.

Construction of Expression Plasmids for Polypeptides. To construct expression plasmids for the polypeptides, synthetic genes encoding $\boldsymbol{B}^{R \boldsymbol{Q}}=\mathrm{R}_{9}, \boldsymbol{B}^{R T}=(\mathrm{RTHRK})_{4}$, and $\boldsymbol{B}^{R Q}=(\text { RQSSRGR })_{2}$ were synthesized by Macrogen (Amsterdam, The Netherlands). A synthetic gene for $\boldsymbol{E}_{40}^{\boldsymbol{S}}$ was designed using the Codon scrambler tool developed by Tang and Chilkoti ${ }^{40}$ and synthesized by GenScript Inc (Piscataway, USA). All the synthetic fragments were designed in order to contain the features necessary for PRe-RDL cloning, as described by McDaniel et al. ${ }^{41}$ Sequences of the DNA fragments used are given in Table S1. The fragments were ligated into separate XbaI/EcorIdigested pET-24a(+) vectors, in order to construct a library of PRe$\mathrm{RDL}$ compatible vectors. A total of $10 \mathrm{ng}$ of plasmid DNA was transformed into Escherichia coli BL21 cells by means of electroporation. Colonies containing the correct DNA inserts were selected and confirmed by DNA sequencing. Next, plasmids for expression of the diblock polypeptides $\boldsymbol{B}-\boldsymbol{E}_{40}^{\boldsymbol{S}}$ were constructed from the PRe-RDL plasmids for the elastin-like protein block $\boldsymbol{E}_{40}{ }_{40}$ and those for the binding blocks $\boldsymbol{B}$, as described by McDaniel et al. ${ }^{41}$ Full amino acid sequences for the diblock polypeptides $\boldsymbol{B}-\boldsymbol{E}^{\boldsymbol{S}}{ }_{40}$ are given in Table S2.

Protein Expression. E. coli BL21 transformed with the expression plasmids for the polypeptides was cultured at $37^{\circ} \mathrm{C} / 200 \mathrm{rpm}$ for $16 \mathrm{~h}$ in $10 \mathrm{~mL}$ of TB medium containing $50 \mu \mathrm{g} / \mathrm{mL}$ kanamycin. A starter culture was inoculated in $2 \mathrm{~L}$ of TB medium containing $50 \mu \mathrm{g} / \mathrm{mL}$ kanamycin and incubated for $24 \mathrm{~h}$ at $37^{\circ} \mathrm{C} / 200 \mathrm{rpm}$. After $8 \mathrm{~h}$ from the start of the incubation, IPTG was added to a final concentration of $1 \mathrm{mM}$ and cells were grown overnight before harvesting.

Protein Isolation and Purification. Bacterial cells were centrifuged at $3300 \mathrm{rpm}$ for $10 \mathrm{~min}$ at $4{ }^{\circ} \mathrm{C}$ and resuspended in 50 $\mathrm{mL}$ of cold phosphate-buffered saline (PBS). Cells were lysed using three cycles of a French press (SLM Aminco). Next, $4 \mathrm{~mL}$ of $10 \%$ (v/ $\mathrm{v})$ polyethyleneamine (PEI) was added to the cell lysates in order to precipitate DNA. The cell lysate was centrifuged for $15 \mathrm{~min}$ at 15,000 rpm at $4{ }^{\circ} \mathrm{C}$ in order to pellet the insoluble fraction. The ELPcontaining polypeptides were first purified using inverse transition cycling. Ammonium sulphate was added to the supernatant to a final concentration of $0.5 \mathrm{M}$. The supernatant was heated to $37^{\circ} \mathrm{C}$ and centrifuged for $10 \mathrm{~min}$ at $15,000 \mathrm{rpm}$ at $37{ }^{\circ} \mathrm{C}$. The pellet was resuspended in $10 \mathrm{~mL}$ of cold $20 \mathrm{mM}$ HEPES pH 8.0 in order to solubilize the aggregated ELP. The ELP-enriched lysate was centrifuged for $10 \mathrm{~min}$ at $15,000 \mathrm{rpm}$ at $4{ }^{\circ} \mathrm{C}$ in order to pellet the remaining insoluble matter. Next, polypeptides were further purified using ion-exchange chromatography. The low ionic strength buffer (buffer A) was $20 \mathrm{mM}$ HEPES $\mathrm{pH}$ 8.0. The high ionic strength buffer was $20 \mathrm{mM}$ HEPES pH 8.0 and $1 \mathrm{M} \mathrm{NaCl}$ (buffer B). Samples were injected in a cation-exchange column (UNO Q6, Bio-Rad Laboratories) and eluted with a linear gradient from buffer A to buffer B. The polypeptides of interest typically eluted at a salt concentration of $0.7 \mathrm{M}$, as found by sodium dodecyl sulfatepolyacrylamide gel electrophoresis (SDS-PAGE) analysis. In some cases, SDS-PAGE indicated that a small amount of impurities was still present. These were then removed using a mild bake-out procedure: solutions were heated at $60^{\circ} \mathrm{C}$ for $15 \mathrm{~min}$, cooled in ice for $10 \mathrm{~min}$, and then centrifuged for $15 \mathrm{~min}$ at $15,000 \mathrm{rpm}$ at $4{ }^{\circ} \mathrm{C}$ in order to pellet the insoluble contaminants. The final purity of the polypeptides was assessed by SDS-PAGE.

Mass Spectrometry. To confirm the identity of the polypeptides, their molecular weights were determined using matrix-assisted laser desorption/ionization (MALDI) mass spectrometry. Spectra were obtained using a Bruker UltraFlextreme machine. Samples were prepared for analysis following the instructions provided by the manufacturer.

$\mathrm{N}$-Terminal Protein Sequencing. N-terminal sequencing was performed by Alphalyse (Odense, Denmark) on an ABI Procise 494 sequencer by Edman degradation chemistry.

Particle Mobility Assay. For glass substrate functionalization, glass slides $(25 \times 75 \mathrm{~mm}$, \#5, Menzel-Gläser) were precleaned by 30 min of sonication in isopropanol (VWR, absolute) and $10 \mathrm{~min}$ of sonication in Milli-Q. After the substrate was dried with a nitrogen stream, 1 min of oxygen plasma was applied to the slides to plasmaoxidize the surface. Custom-made fluid cell stickers (Grace Biolabs) with an approximate volume of $20 \mu \mathrm{L}$ were then attached to the substrate and $0.5 \mathrm{mg} / \mathrm{mL}$ of PLL-g-PEG solution in Milli-Q respectively. $0.5 \mathrm{mg} / \mathrm{mL}$ of $B^{R T}-E_{40}^{S}$ solution in Milli-Q was immediately injected to the flow chamber and incubated for $5 \mathrm{~h}$ at room temperature.

For particle functionalization, vials with carboxyl-functionalized silica particles (Bangs Laboratories, $1 \mu \mathrm{m}$ mean diameter) at a concentration of $1 \mathrm{mg} / \mathrm{mL}$ were incubated with, respectively, $0.9 \mathrm{mg} /$ $\mathrm{mL}$ of $\boldsymbol{B}^{R T}-\boldsymbol{E}_{40}^{S}$ in Milli-Q and $0.9 \mathrm{mg} / \mathrm{mL}$ of PLL- $g$-PEG in Milli-Q and placed on a rotating fin (VWR, The Netherlands) for $3 \mathrm{~h}$ at room temperature. Streptavidin-coated polystyrene superparamagnetic particles $(10 \mathrm{mg} / \mathrm{mL}$, Dynabeads MyOne Streptavidin C1, 65001, Thermo Scientific) at a concentration of $1 \mathrm{mg} / \mathrm{mL}$ in PBS $(130 \mathrm{mM}$ $\mathrm{NaCl}, \mathrm{pH} 7.4)$ were incubated with $5 \mu \mathrm{L}$ of 11 nt ssDNA (5' TCACGGTACGA 3' Biotin, Integrated DNA Technologies) at a concentration of $2 \mu \mathrm{M}$ in PBS and mPEG-Biotin (PG1-BN-1k, Nanocs) at a concentration of $100 \mu \mathrm{M}$ in PBS buffer for 70 min on a rotating fin. The particle mixtures were washed with 0.05 vol \% Tween-20 (Sigma-Aldrich) and reconstituted in $1000 \mu \mathrm{L}$ of PBS (130 $\mathrm{mM} \mathrm{NaCl}, 7 \mathrm{mM} \mathrm{Na}_{2} \mathrm{HPO}_{4}$, and $3 \mathrm{mM} \mathrm{NaH}_{2} \mathrm{PO}_{4}$ at $\mathrm{pH}$ 7.4). Right before injecting particles to the flow chamber, the particle solution was sonicated with 10 pulses at $70 \%$ with 0.5 duty cycle (Hielscher, Ultrasound Technology).

For the particle mobility assay, particles with different modifications were added to the variously modified surfaces at a final concentration of $0.01 \mathrm{mg} / \mathrm{mL}$ in PBS. The trajectory of the particles was recorded for 1 and $5 \mathrm{~min}$ at a frame rate of 30 and $60 \mathrm{~Hz}$ with an integration time of $5 \mathrm{~ms}$ in a field of view of $883 \times 552 \mu \mathrm{m}^{2}$ with the Leica microscope (Dark field microscopy, Leica DMI5000M). By applying a Gaussian fitting over the intensity of pixels around the particle, the center of every particle can be determined to within approx. $20 \mathrm{~nm}$ and tracked over all frames.

\section{RESULTS AND DISCUSSION}

At neutral $\mathrm{pH}$, silica has a weak negative charge. ${ }^{42}$ Under these conditions and at low ionic strength, arginine has been found to adsorb most strongly to silica compared to the natural amino acids, ${ }^{43}$ at least in part due to the high $\mathrm{pKa}$ of its side chain. Indeed, in sequences of many SBPs, arginine is overrepresented. While many sequences have been reported as being SBPs, a detailed characterization of their binding to silica has only been carried out for a few. Here, we choose to explore 
two of these, that is, $B^{R T}$ and $B^{R Q}$, plus oligoarginine control peptides $\boldsymbol{B}^{\boldsymbol{R}_{n}}=\mathrm{R}_{n}$, as binding domains $\boldsymbol{B}$. The peptides were fused to ELP (repeat sequence of VPGSG) in order to generate brush-like diblocks $\boldsymbol{B}-\boldsymbol{E}_{40}^{S}$ (Figure 2).

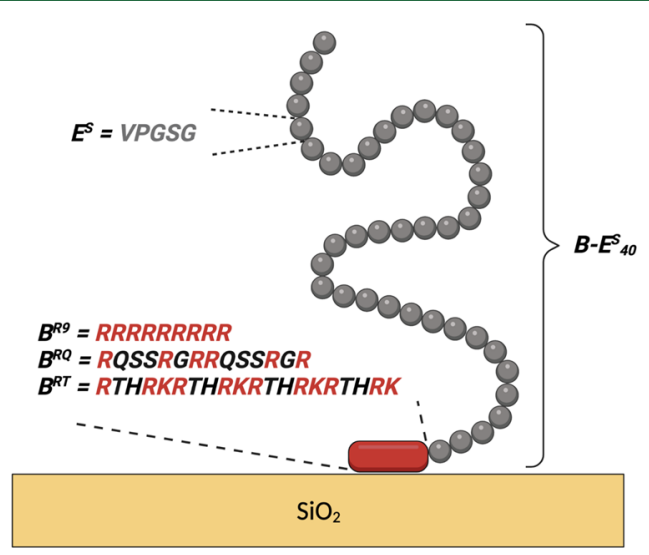

Figure 2. Schematic structure of $\boldsymbol{B}-\boldsymbol{E}_{40}^{\boldsymbol{S}}$ diblocks for forming hydrophilic polypeptide brushes on silica surfaces.

The first SBP characterized is the highSP peptide ${ }^{44,45}$ which was engineered from a weaker binding precursor isolated from E. coli. ${ }^{46}$ The sequence of highSP will be referred to as $B^{R T}$, after the first two residues, $B^{R T}=(\mathrm{RTHRK})_{4} \cdot B^{R T}$ shows high affinity to silica, zinc, and other oxidized metals and has already been successfully employed as a binding tag. ${ }^{44,47}$ A second SBP that was evaluated is peptide SB7, which was isolated from the spore-coat protein CotB1 of Bacillus cereus. ${ }^{43}$ Its sequence will be referred to as $B^{R Q}$, again after the first two residues, $B^{R Q}=$ (RQSSRGR) $)_{2}$. This peptide was designed as a short affinity purification tag, using silica-based materials.

Representative QCM-D data for the adsorption of the SBP $B^{R T}$ in $\mathrm{PB}$ to silica are shown in Figure 3a. The lowest concentration for which we observe significant binding is slightly below $1 \mu \mathrm{M}$. For this concentration, as well as for higher concentrations, adsorbed peptide layers form in less than $10 \mathrm{~min}$. Flushing with PB buffer for $10 \mathrm{~min}$ does not lead to significant detachment of the adsorbed peptides. The out-ofphase response, or energy dissipation, is minimal and so was the dispersion between frequency shifts for different harmonics, indicating a rigidly adsorbed peptide layer that covibrates with the crystal oscillations.

Eventually, we wish to construct diblock polypeptides $B-$ $\boldsymbol{E}_{40}^{\boldsymbol{S}}$ with solid-binding domains $\boldsymbol{B}$ and long hydrophilic ELP domains $\boldsymbol{E}_{40}{ }_{40}$, where $\boldsymbol{E}^{\boldsymbol{S}}=$ VPGSG. For efficient brush formation, the much longer hydrophilic blocks should not compete with the binding blocks in binding to the silica. For example, it is well-known that PEG has a strong affinity for silica, ${ }^{48}$ which for PLL-g-PEG polymers may compete with the PLL backbone in adsorbing to silica surfaces. Therefore, we also performed QCM-D measurements on the adsorption of the short elastin-like peptide $\boldsymbol{E}_{3}{ }_{3}$ to silica. These results are included in Figure 3a. Within the accuracy of the instrument, we could not detect any adsorption of the elastin-like peptide, suggesting that this ELP is indeed a good choice as a hydrophilic block when aiming to construct self-assembling brushes on silica.

Since the out-of-phase response or dissipation $D$ in the QCM-D experiments was shown to be negligible and there was hardly any dispersion between frequency shifts for different
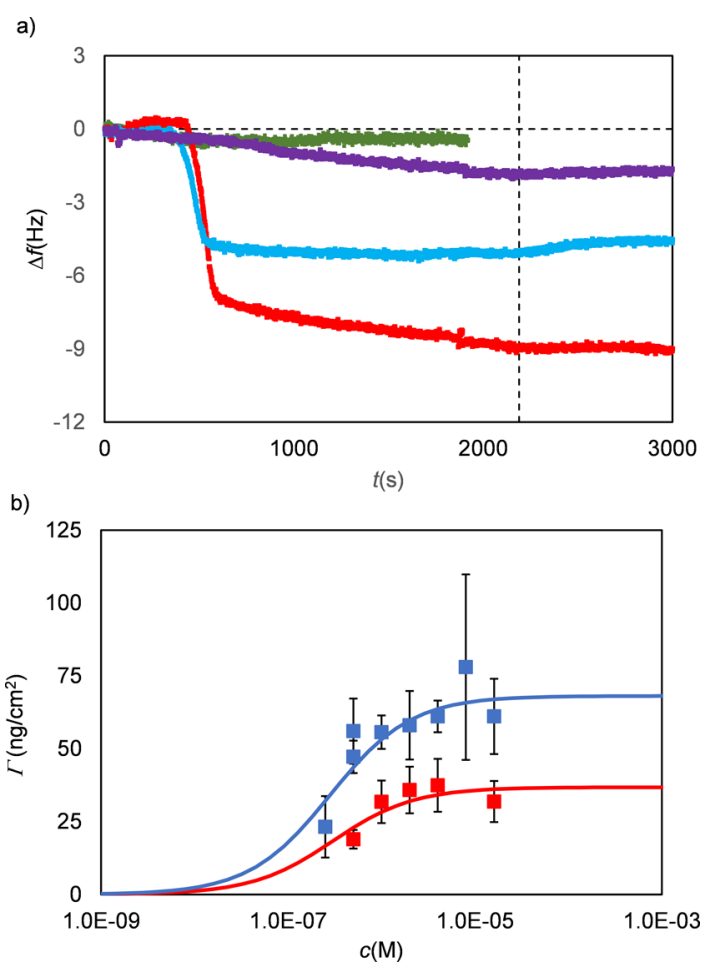

Figure 3. Representative QCM-D data for the adsorption of the SBP $B^{R T}$ and the short ELP $E_{3}^{S}$ to silica. (a) Frequency $\Delta f(\mathrm{~Hz})$ shift vs time $t(\mathrm{~s})$ for $\boldsymbol{B}^{R T}$ at increasing peptide concentrations (purple, 0.175 $\mu \mathrm{M}$; blue, $5 \mu \mathrm{M}$; and red, $10 \mu \mathrm{M}$ ) and for $\boldsymbol{E}_{3}^{S}$ (green, $5 \mu \mathrm{M}$ ). The vertical dashed line indicates the start of washing with buffer (PB). (b) Representative curve of saturation adsorbed mass $\Gamma\left(\mathrm{ng} / \mathrm{cm}^{2}\right)$ vs peptide concentration $c(\mathrm{M})$ for the SBP $B^{R T}$. Blue filled squares: adsorption from $\mathrm{PB}$ buffer and red filled squares: adsorption from PBS buffer. Data were fitted using Langmuir isotherms (solid lines) to obtain apparent dissociation constants $K_{\mathrm{d} \text {,app }}\left(\mathrm{M}^{-1}\right)$ and maximum adsorbed masses $\Gamma_{\max }$ (Table 2). Error bars are standard deviations for $>3$ independent measurements.

harmonics, the Sauerbrey equation can be applied to relate the frequency shift to adsorbed mass per unit area. ${ }^{14}$ Results for the saturation values of the adsorbed mass per unit area $\Gamma$ as a function of peptide concentration $c$ (in M) for the SBP $B^{R T}$ are shown in Figure $3 \mathrm{~b}$. Results for the other SBPs, $B^{R Q}$ and $B^{R 14}$, were very similar and are shown in Figure S1. A Langmuir equation was applied to fit the data to get apparent dissociation constants $K_{\mathrm{d} \text {,app }}$ and plateau values $\Gamma_{\max }$ for the adsorbed mass per unit area.

Strictly speaking, the validity of the Langmuir equation requires that the peptides are noninteracting on the surface and that the adsorbed layer is in full equilibrium. For all three peptides, $B^{R T}, B^{R Q}$, and $B^{R 14}$, there are strong indications for irreversible rather than equilibrium adsorption and for an important role for peptide-peptide interactions at the solvent-silica interface. Hence, it is unlikely the peptides satisfy the requirements for the validity of the Langmuir equation. Therefore, we prefer to denote the dissociation constants obtained by the Langmuir fits of the QCM data as apparent dissociation constants $K_{\mathrm{d} \text {,app }}$.

Values for dissociations constants $K_{\mathrm{d} \text {,app }}$ and plateau values $\Gamma_{\max }$ are listed in Table 2. Within the rather large error of the measurements, there are no significant differences in the apparent dissociation constants of the peptides. Apparent dissociation constants $K_{\mathrm{d} \text {,app }}$ for all three peptides are on the 
Table 2. Parameters from Langmuir Fits of QCM-D Data

\begin{tabular}{cccccc} 
& \multicolumn{3}{c}{ PB } & & \multicolumn{2}{c}{ PBS } \\
\cline { 2 - 3 } \cline { 5 - 6 } peptide & $\begin{array}{c}K_{\mathrm{d} \text {,app }} \\
{\left[10^{6} \mathrm{M}^{-1}\right]}\end{array}$ & $\begin{array}{c}\Gamma_{\max } \\
{\left[\mathrm{ng} / \mathrm{cm}^{2}\right]}\end{array}$ & & $\begin{array}{c}K_{\mathrm{d} \text {,app }} \\
{\left[10^{6} \mathrm{M}^{-1}\right]}\end{array}$ & $\begin{array}{c}\Gamma_{\max } \\
{\left[\mathrm{ng} / \mathrm{cm}^{2}\right]}\end{array}$ \\
$\boldsymbol{B}^{R 14}$ & 1.4 & 90 & & 0.7 & 70 \\
$\boldsymbol{B}^{R T}$ & 3.6 & 70 & & 3.3 & 40 \\
$\boldsymbol{B}^{R Q}$ & 2.5 & 40 & & 0.5 & 40 \\
\hline
\end{tabular}

order of $\mu \mathrm{M}$. Saturation densities are on the order of $0.5 \mathrm{mg} /$ $\mathrm{m}^{2}$. Both are fairly typical for adsorbed peptide layers. ${ }^{14,49,50}$ The saturation density corresponds to an approximate surface area per peptide on the order of $5 \mathrm{~nm}^{2}$.

Next, we have attempted to image the ultrastructure of the adsorbed peptide layers by performing AFM imaging on dried peptide layers in air. Control measurements of clean silica slides did not show any feature with heights in excess of 200 pm. AFM images show surface features that are strongly dependent on the concentrations at which the layers are formed. For all peptides, at low concentrations, we observe a homogeneous background and small globular features, whereas at higher concentrations, a homogeneous background and surface-bound fibrils are observed. Selected results for the SBP $B^{R T}$ are shown in Figure $4 a-c$; an overview with results for all SBPs and concentrations tested is shown in Figure S2.

For the solid-binding peptides $B^{R T}$ and $B^{R Q}$, surface-bound fibrils were observed when adsorption was performed at concentrations above about $5 \mu \mathrm{M}$, whereas for the $B^{R 14}$ control peptide, surface-bound fibrils were already observed at concentrations of around $0.5 \mu \mathrm{M}, 1$ order of magnitude lower. For each peptide, cross sections of multiple fibrils $(n=$ 6) were analyzed and average fibril heights $h_{\text {fibril }}$ were calculated. Fibril heights for different peptides were similar, $h_{\text {fibril }}=0.8 \pm 0.2 \mathrm{~nm}$ for $B^{R T}, h_{\text {fibril }}=0.5 \pm 0.2 \mathrm{~nm}$ for $B^{R Q}$, and $h_{\text {fibril }}=0.9 \pm 0.4 \mathrm{~nm}$ for $B^{R 14}$. It should be noted that drying may have had some impact on the final morphology of the fibrils as imaged. This could possibly be checked by complementary AFM imaging experiments in liquid.

In order to establish whether fibril formation is induced by the silica surface or if fibrils form in solution and subsequently adsorb, we have monitored peptide solutions for long periods using DLS. Results are shown in Figure 4d. Peptide solutions of $1 \mathrm{mg} / \mathrm{mL}$ were carefully filtered and sonicated in order to ensure that no aggregates were present at the start of the measurement. The concentration of $1 \mathrm{mg} / \mathrm{mL}$ is well above the concentrations for which fibrils were observed in the AFM images. Hydrodynamic radii were measured for $1 \mathrm{~h}$. During this time, the hydrodynamic diameter $\left(D_{\mathrm{H}}\right)$ that was observed remained small, in the order of $2.5 \mathrm{~nm}$, which is the size expected for monomeric peptides in solution. Samples measured again over 3 days and 1 week did not show any noticeable change in hydrodynamic size either (data not shown). Hence, fibril formation of the SBPs appears to be driven by interaction with silica surfaces and not start in the bulk solution.

Having established that the SBPs strongly interact with each other when adsorbed to silica surfaces, it is clear that a simple Langmuir adsorption isotherm cannot be used to describe the mechanism of peptide surface layer formation, even though the data of saturation adsorption $\Gamma_{\max }$ versus concentration $c$ can be fitted with a Langmuir isotherm.

To obtain information on the binding of individual SBPs to silica, in the absence of peptide-peptide interactions, we resort to the measurement of single-molecule force-extension curves
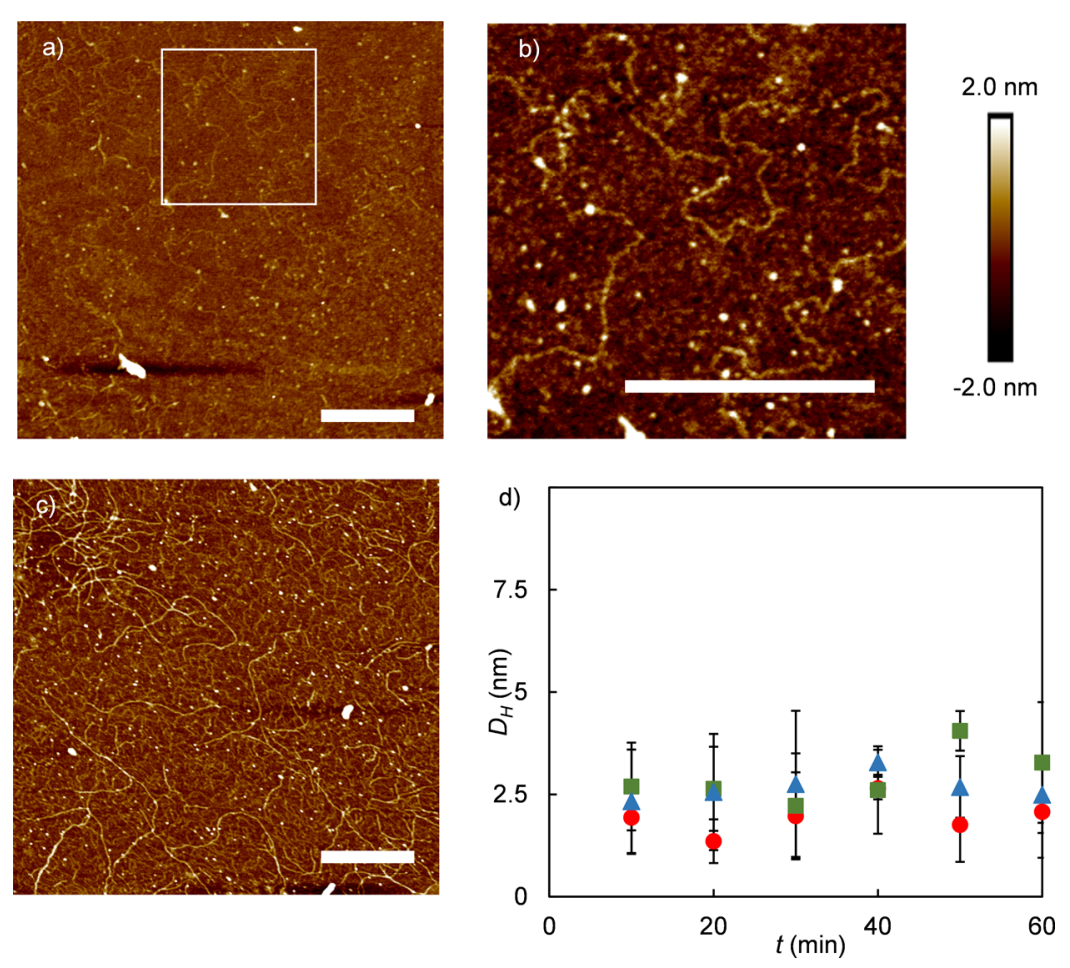

Figure 4. Surface-induced fibril formation for SBP $B^{R T}$ on silica. (a-c) AFM images of $B^{R T}$ adsorbed onto silica from PB buffer and incubated for 1 $\mathrm{h}$, imaged in air, for different concentrations and magnifications. Scale bars are $200 \mathrm{~nm}$. (a) $3.66 \mu \mathrm{M}$, (b) zoom-in of region outlined in (a). (c) 36.6 $\mu \mathrm{M}$. (d) Hydrodynamic diameter $D_{\mathrm{H}}(\mathrm{nm})$ from DLS of $1 \mathrm{mg} / \mathrm{mL}$ SBP solutions in PB, as a function of time. Red circle: $\boldsymbol{B}^{R Q}$, green square: $\boldsymbol{B}^{R T}$, and blue triangle: $B^{R 14}$. 
a)

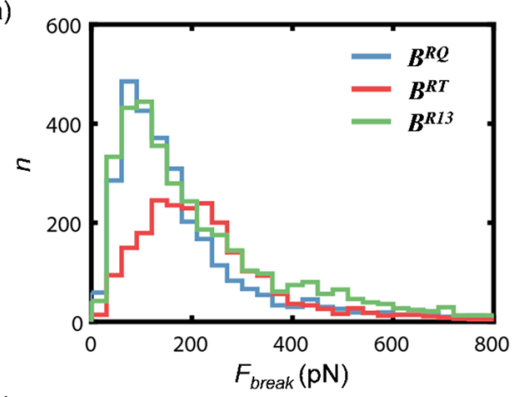

c)

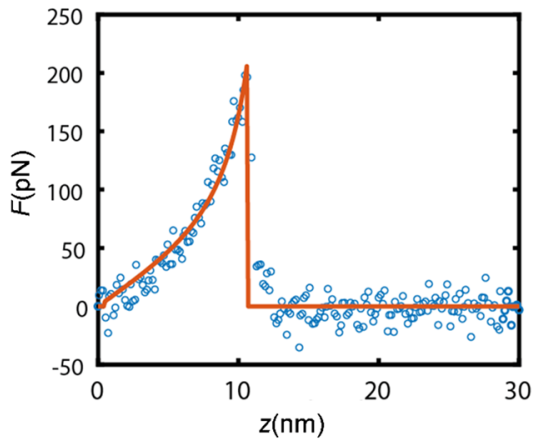

b)

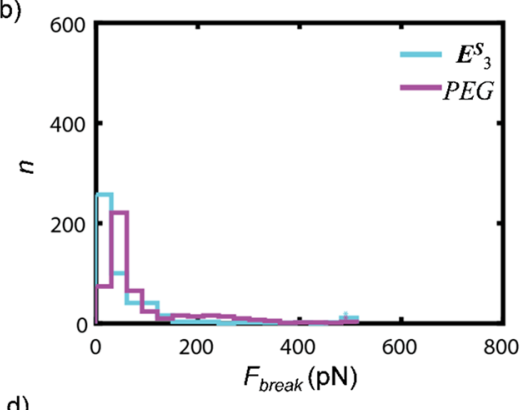

d)

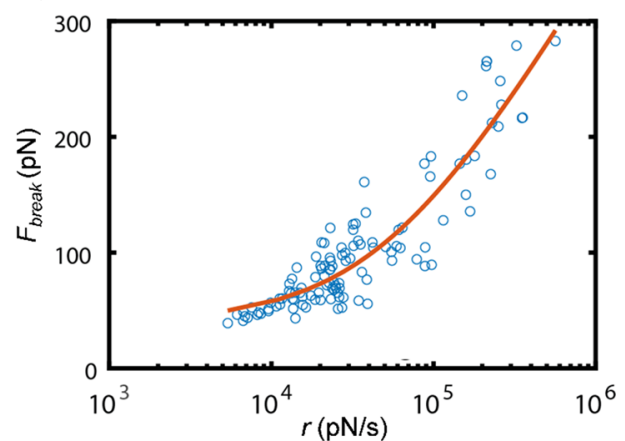

Figure 5. Single-molecule AFM-based force spectroscopy. (a) Histogram of the number of events $n$ vs breaking force $F_{\text {break }}$ (pN) for SBPs $B^{R Q} C_{-} y s$, $B^{R T}-C y s$, and $B^{R 13}-C y s$ (as indicated). (b) Histogram of the number of events $n$ vs breaking force $F_{\text {break }}$ (pN) for negative controls (as indicated): just the PEG linker (no peptide conjugated) and the nonadsorbing elastin-like peptide $\boldsymbol{E}_{3}^{S}$. (c) Example fit of single force curve for $\boldsymbol{B}^{R 13}$ - $C y s$ with the FJC used to extract approximate numbers of parallel peptides $M$ and contour lengths $L_{c}$. (d) Final result of data analysis, for the case of $B^{R T}$ Cys: breaking force $F_{\text {break }}(\mathrm{pN})$ versus loading rate $r(\mathrm{pN} / \mathrm{s})$, for selected event with $M=1, \ldots, 7$. The red line is the fit with the Friddle-deYoreo model; fit parameters for all SBPs are given in Table 4.

using AFM. An AFM tip is functionalized with maleimideterminated PEG linkers, to which cysteine-terminated SBPs are attached via thiol bonds at a low density, as sketched in Figure $\mathrm{S} 3 \mathrm{a}$. As shown in Figure S4d-f, with this procedure, there are typically a small number of peptides $M<30$ that interact simultaneously with the surface. ${ }^{38}$ The low density guarantees that during the experiments, peptides do not interact with each other.

The peptides studied here consist of no more than 21 amino acids, while the PEG linker has an average number of 27 repeat units; assuming an approximate size of $0.4 \mathrm{~nm}$ per monomer, a total contour length for the constructs of approximately $20 \mathrm{~nm}$ can be calculated. The absence of attraction at distances larger than this cutoff was used as a first selection criterion to identify relevant events. Histograms of rupture forces for the SBPs and the negative controls (respectively, the inert ELP peptide $\boldsymbol{E}_{3}^{S}$ and the nonfunctionalized PEG linkers) are shown in Figure 5a,b. As expected, for the SBPs, we find a large number of rupture events and forces at rupture of order $100 \mathrm{pN}$. In contrast, for the negative controls, the number of events for which a rupture is detected is much lower, and typical rupture forces are lower, thus validating that in our experiment, we indeed measure adhesion forces of SBPs for the silica substrate. A typical force-extension curve for the SBP $B^{R 13} C y s$ is shown in Figure 5c. All force-extension curves such as this one were fit with an FJC model for $M$ parallel chains, to give the contour length $L_{\mathcal{c}}$, breaking force $F_{\text {break }}$ and loading rate $r$ at rupture, as well as an estimate of the number $M$ of parallel chains in the rupture event. While most force-extension curves showed only a single rupture event and hence could be analyzed as described above, a small number of force-extension curves were also recorded that showed rupture in multiple steps. ${ }^{51}$ These rare events were excluded from the analysis. We find that most rupture events have a number of parallel bonds $M<$ 10. To ensure that we measure binding and unbinding of individual peptides, we focus on the events corresponding to a low number of parallel bonds, $M=1, \ldots, 7$. Histograms of the contour length $L_{\mathrm{c}}$ and the number of parallel bonds $M$ are presented in Figure S4. For data with $M=1, \ldots, 7$, rupture force versus loading rate was analyzed using the Friddle-de Yoreo (FdY) model for $M$ parallel bonds that can detach and reattach. $^{38,52}$ The FdY model has been used before to analyze the adhesion of proteins to substrates ${ }^{53,54}$ of polymer to minerals ${ }^{55}$ and of peptides to inorganic materials. ${ }^{56}$ At low loading rates, the rapid (re)binding and unbinding leads to a constant rupture force, but at higher loading rates, the model recovers the known logarithmic loading-rate dependence for the case in which rebinding is neglected. ${ }^{38}$ An example fit for the SBP BRT is shown in Figure 5d, fits for the other SBPs are given in Figure S3b,c. Fit parameters for all SBPs are listed in Table 3. An approximate binding free energy $\Delta G$ is calculated from the fitted $F_{\text {eq }}$ using a relation previously derived by Manohar, ${ }^{39}$ these values are also included in Table 3.

Of special attention are the relatively high off-rates, for example, $k_{\text {off }} \approx 2.9 \cdot 10^{2} \mathrm{~s}^{-1}$ for $\boldsymbol{B}^{R T}$, although still not as high as found previously $\left(k_{\text {off }} \approx 2.6 \cdot 10^{3} \mathrm{~s}^{-1}\right)$ for the adhesion of an even shorter and more weakly adhering peptide (GCRL) to

Table 3. Fit Parameters for FdY Fits of Rupture Force Versus Loading Rate for SBP, Binding to Silica

$\begin{array}{lcccc}\mathrm{SBP} & k_{\text {off }}\left(\mathrm{s}^{-1}\right) & x_{\mathrm{t}}(\AA) & F_{\text {eq }}(\mathrm{pN}) & \Delta G\left(k_{\mathrm{B}} T\right) \\ \boldsymbol{B}^{R 13} & 145.9 & 0.6 & 29.4 & 2.62 \\ \boldsymbol{B}^{R Q} & 246.4 & 0.3 & 46.1 & 3.81 \\ \boldsymbol{B}^{R T} & 287.4 & 0.4 & 40.0 & 3.36\end{array}$


a)

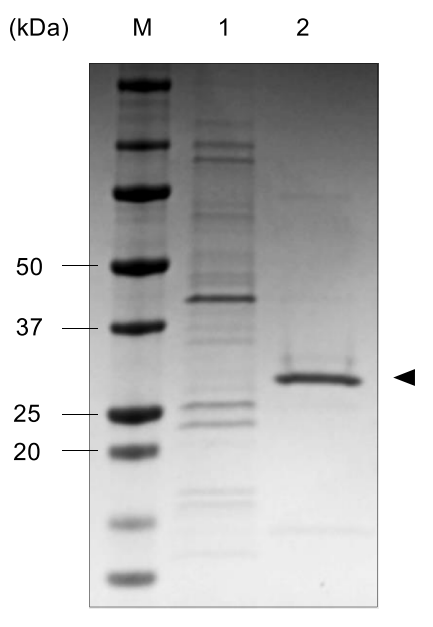

b)

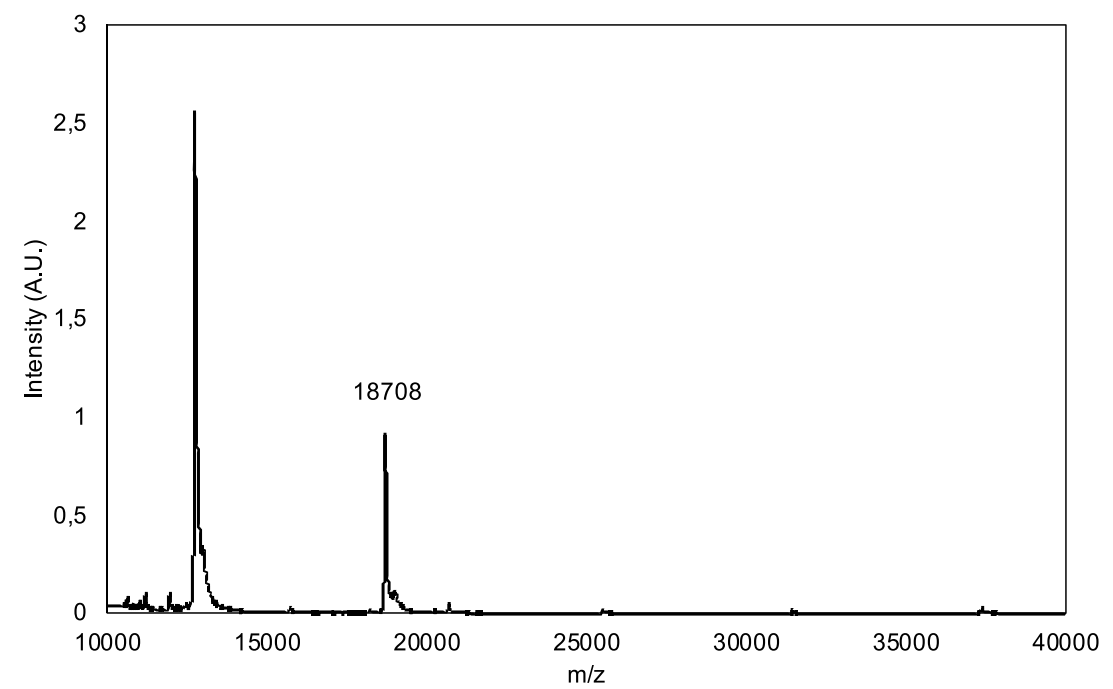

Figure 6. Purification and characterization of recombinant $\boldsymbol{B}-\boldsymbol{E}_{40}{ }_{40}$ diblock polypeptides, example data for $\boldsymbol{B}^{R T}-\boldsymbol{E}_{40}{ }_{40}$. (a) SDS-PAGE analysis. Lane 1: insoluble pellet; lane 2: purified polypeptide; and lane M: molecular mass marker. (b) MALDI-TOF spectrum.

silica. ${ }^{51}$ Hence, our data demonstrate that single SBPs detach rapidly, thereby supporting the hypothesis that the relative stability of SBP layers is caused by SBP-SBP interactions at the silica surface, which reinforce the surface layers.

Having established that all SBPs bind with similar affinities and have similar off-rates but form peptide layers that are not easily detached, $\boldsymbol{B}-\boldsymbol{E}^{\boldsymbol{S}}{ }_{40}$ diblock polypeptides were generated with binding blocks $B=B^{R T}, B^{R Q}$, and $B^{R 9}$. A shorter $\mathrm{R}_{\mathrm{n}}$ block was used for the experiments with synthetic peptides $\left(B^{R 9}\right.$ instead of $B^{R 14}$ ) since highly cationic polypeptides are often difficult to express in view of their possible toxicity to the production host, in our case E. coli.

Three fusion proteins were successfully produced and purified from E. coli. Representative SDS-PAGE and MALDITOF results for $B^{R T}-E^{S}{ }_{40}$ are shown in Figure 6. As expected, the overexpressed polypeptides are not found in the insoluble cell pellet (Figure 6a) but rather in the soluble extract obtained after cell disruption. The presence of positively charged silicabinding domains $\boldsymbol{B}$ in the fusion proteins was exploited for purification using cation-exchange chromatography. This allowed for nearly complete purification in one step. A final mild bake-out procedure was sufficient to further purify the desired proteins to an acceptable level (Figure 6a). As previously observed, ${ }^{57,58}$ the poor SDS-binding of ELPs leads to anomalously high molecular weights in SDS-PAGE when compared with globular protein molecular weight standards. To confirm the identity of the polypeptides, MALDI-TOF spectra were determined for the purified proteins (Figure $6 \mathrm{~b}$ ). The experimentally determined masses corresponded well with the theoretically expected values, as shown in Table 4. A further confirmation was obtained via $\mathrm{N}$-terminal protein sequencing (data not shown).

Next, layer formation on silica surfaces was studied using QCM-D for the $B-E^{S}{ }_{40}$ diblocks and compared to that of the binding blocks $B$ alone. A representative comparison for $1 \mu \mathrm{M}$ $B^{R T}$ peptide versus the same molar concentration of $B^{R T}-E_{40}^{S}$ diblock polypeptide is shown in Figure 7. At this concentration, saturated layers were formed for both the peptide and the diblock polypeptide. The curves of the frequency shift $\Delta f$ and dissipation $D$ versus time are
Table 4. Molecular Weights of Diblock Polypeptides $B-E_{40}^{S}$ as Computed from the Amino Acid Sequence and as Determined Using MALDI-TOF

\begin{tabular}{ccc} 
diblock polypeptide & $M_{\text {theo }}(\mathrm{kg} / \mathrm{mol})$ & $M_{\text {exp }}(\mathrm{kg} / \mathrm{mol})$ \\
$\boldsymbol{B}^{R 9}-\boldsymbol{E}_{40}^{S}$ & 17.452 & 17.458 \\
$\boldsymbol{B}^{R Q}-\boldsymbol{E}_{40}^{S}$ & 17.645 & 17.652 \\
$\boldsymbol{B}^{R T}-\boldsymbol{E}_{40}^{S}$ & 18.704 & 18.708 \\
\hline
\end{tabular}

substantially different for the two cases: for the diblock polypeptide, both the frequency shift and the dissipation are much higher. This indicates that due to the $\boldsymbol{E}_{40}^{S}$ tails, not only the adsorbed mass per unit area is much higher but also that the highly hydrated nonadsorbed $E_{40}^{S}$ tails do not covibrate with the quartz crystal, in contrast to the strongly adsorbed $B^{R T}$ domains, leading to high dissipation. ${ }^{59}$ Similar results were found for the other diblock polypeptides $B^{R Q}-E_{40}^{S}$ and $B^{R 9}-$ $\boldsymbol{E}_{40}^{S}$. This confirms that the diblock polypeptides do indeed form self-assembled $\boldsymbol{E}_{40}{ }_{40}$ brushes as intended.

Given the complexities and uncertainties in precisely fitting QCM-D data for cases when significant dissipation is present, ${ }^{3}$ the frequency change $\Delta f$ was used instead as a qualitative measure for the adsorbed amount. Limiting values of the frequency change $\Delta f$ versus concentration are shown in Figure 8 , whereas for the individual binding blocks, we found that saturated layers were formed at concentrations around approximately $1 \mu \mathrm{M}$, and for the diblock polypeptides, it seems that a saturation value for the frequency change is already reached at concentrations well below $1 \mu \mathrm{M}$. This could be caused by the steric repulsion of the $\boldsymbol{E}_{40}^{S}$ tails limiting further adsorption as was also found for similar diblock polypeptides adhering to double-stranded DNA. ${ }^{60}$

Some further aspects of the polypeptide brushes selfassembled from $\boldsymbol{B}-\boldsymbol{E}_{40}^{\boldsymbol{S}}$ on silica were investigated for the specific case of $\boldsymbol{B}=\boldsymbol{B}^{R T}$. First, we consider the dependence of brush formation on solution conditions. The adsorption of the cationic-binding peptides being largely electrostatically driven, we expect a significant dependence of the layer formation on ionic strength. Indeed, this is borne out by the QCM-D results shown in Figure 9. 
a)

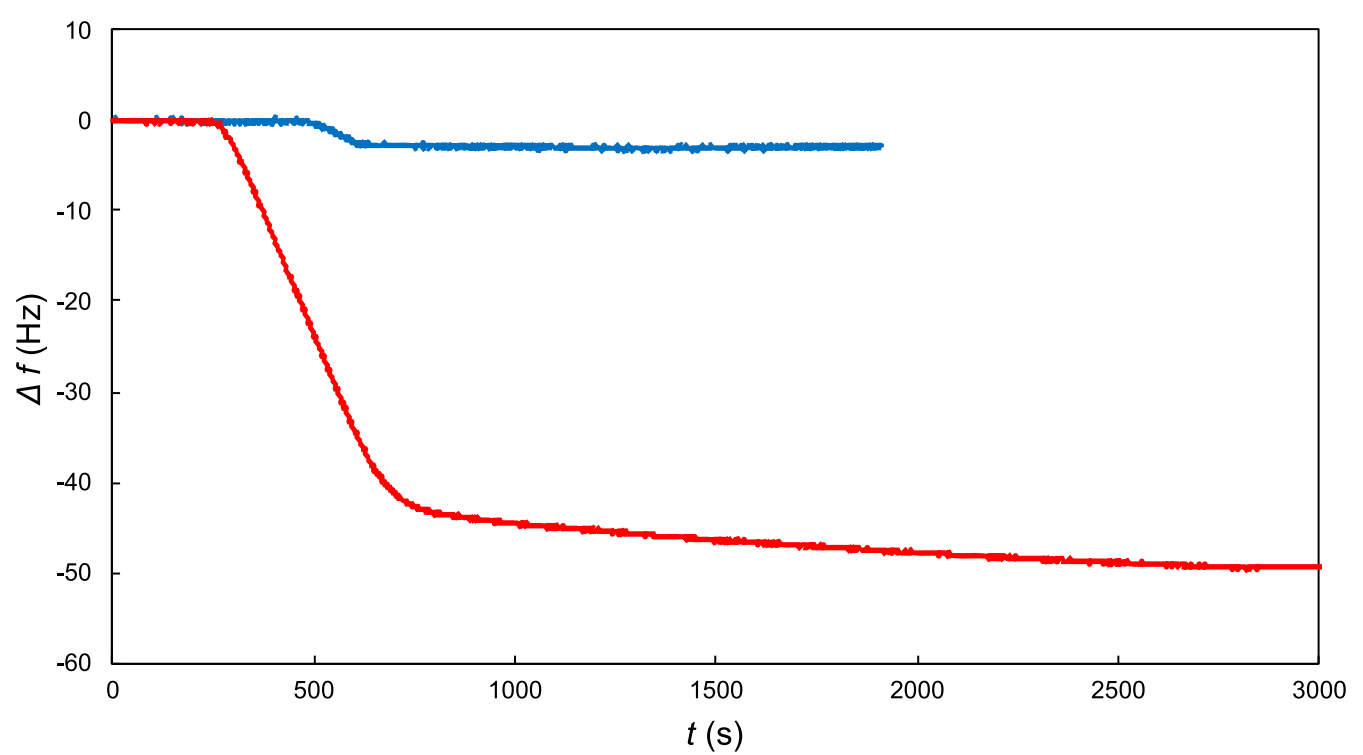

b)

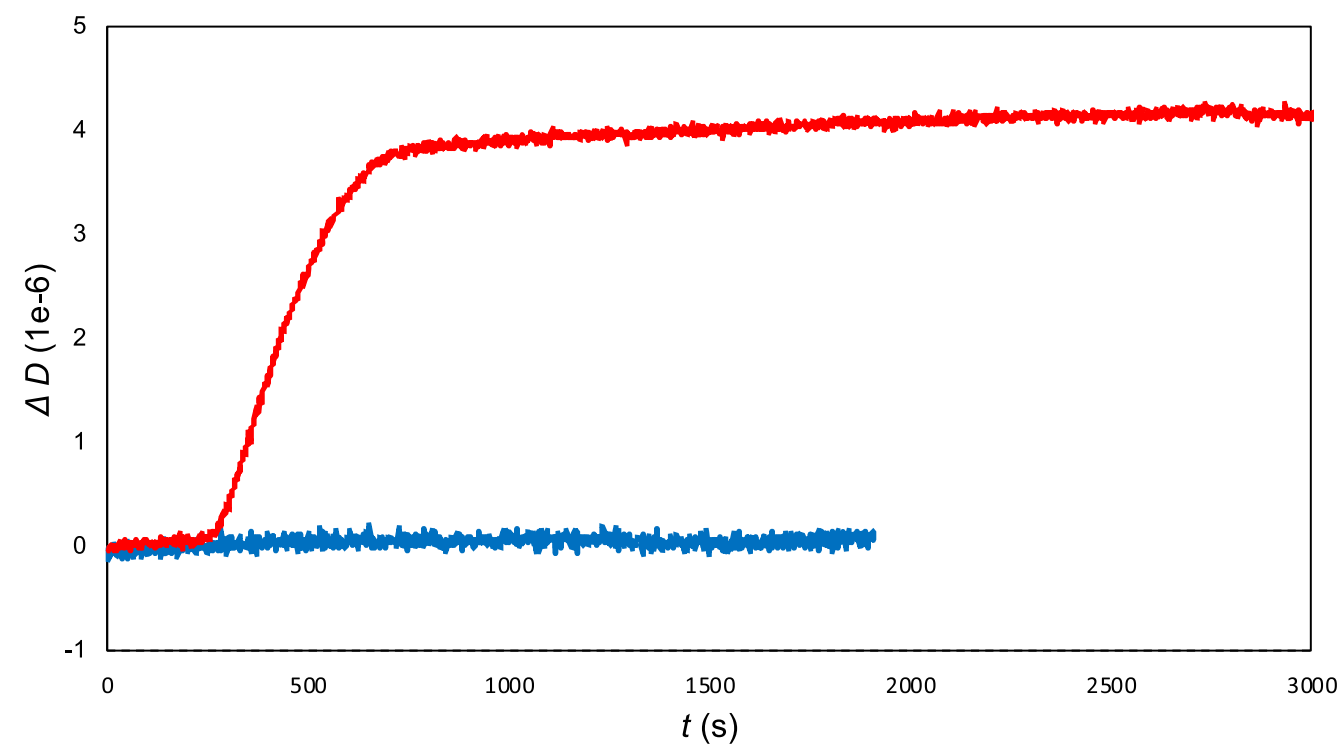

Figure 7. Representative comparison of $\mathrm{QCMD}$ data for adsorption to silica for $1 \mu \mathrm{MB}-\boldsymbol{E}_{40}^{S}$ diblock polypeptides with the corresponding data for the SBP $B$. Red: diblock polypeptides $B^{R T}-E_{40}^{S}$ and blue: SBP $B^{R T}$. (a) Frequency shift vs time. (b) Dissipation vs time.

As shown in Figure 9a, an adsorbed layer is rapidly formed when flowing a solution of $5 \mu \mathrm{M}$ of $B^{R T}-E^{S}$ in $\mathrm{PB}$ over a clean silica surface. Upon rinsing with $\mathrm{PB}$ buffer, there is negligible change in the frequency shift, indicating minimal desorption, as was also found for the peptide binding blocks $B$ by themselves. Upon shifting to PBS (=PB $+150 \mathrm{mM} \mathrm{NaCl})$, a significant decrease is observed for the magnitude of the frequency shift. Finally, upon flushing in $\mathrm{PB}+500 \mathrm{mM} \mathrm{NaCl}$, the frequency shift drops nearly to the baseline. A separate channel was used to correct for the effect of the buffer by itself on the crystal oscillation frequency. The experiments indicate that the salt stability of the self-assembly polypeptide brushes is at best moderate.

In another QCM-D experiment, brushes were assembled at different ionic strengths rather than exposed to a higher ionic strength after having been formed at low ionic strength. Results are shown in Figure $9 \mathrm{~b}$. A $5 \mu \mathrm{M}$ solution of $B^{R T}-E_{40}^{S}$ in either $\mathrm{PB}$ or PBS was flown over a clean silica sensor. After a saturated layer had formed, the sensor was rinsed with either $\mathrm{PB}$ or PBS for $4 \mathrm{~h}$ and the shift in frequency of the sensor was monitored. We find that the frequency shift for assembly in PBS is nearly but not exactly the same, as the shift when the layer is first formed in $\mathrm{PB}$ and subsequently exposed to PBS. Note that for this experiment, we performed prolonged rinsing with buffer and even after many hours of rinsing, there is hardly any shift in frequency. This indicates that for a given buffer composition, there is hardly any polypeptide desorption neither when rinsing with $\mathrm{PB}$ for saturated layers formed in $\mathrm{PB}$ nor for PBS for saturated layers formed in PBS.

The self-assembled polypeptide brushes could be used to stabilize and functionalize not only macroscopic flat silica surfaces but also silica nano- and microparticles. To investigate brush formation around silica nanoparticles, DLS was performed on nonporous silica particles with a reported hydrodynamic diameter of $D_{\mathrm{H}}=163 \mathrm{~nm}$. A dilute suspension of these particles was incubated for $5 \mathrm{~min}$ with varying 


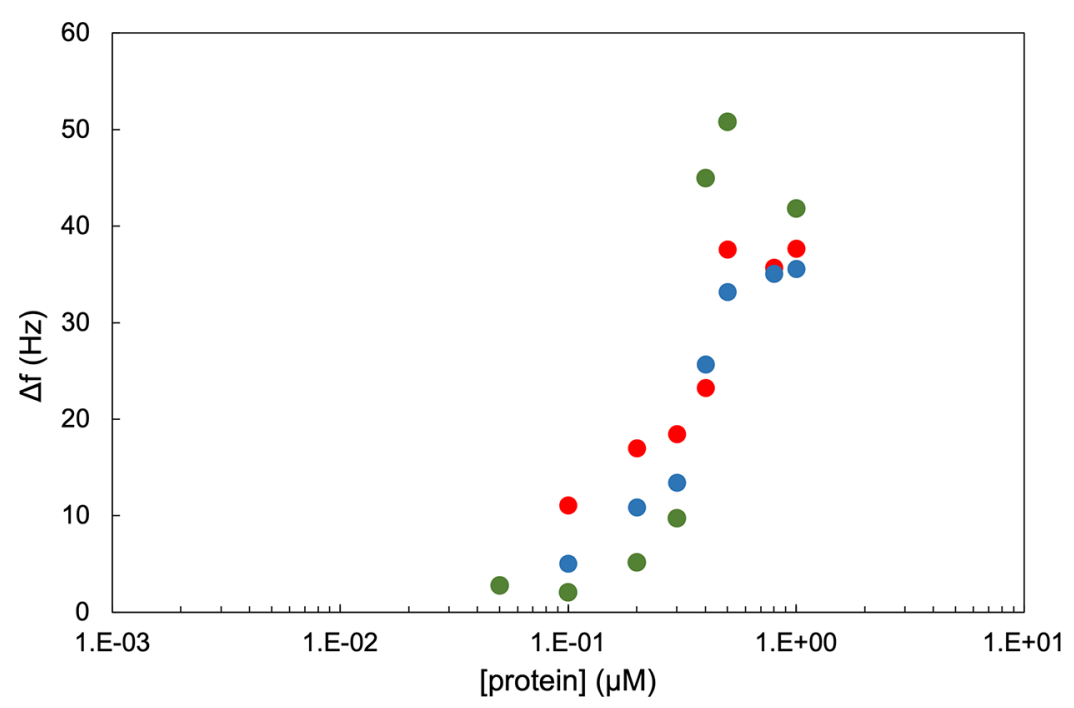

Figure 8. Limiting frequency shifts $\Delta f$ for $\boldsymbol{B}-\boldsymbol{E}_{40}^{S}$ diblocks versus polypeptide concentration $c(\mu \mathrm{M})$. Green: $\boldsymbol{B}=\boldsymbol{B}^{R T}$, blue: $\boldsymbol{B}=\boldsymbol{B}^{R Q}$, and red: $\boldsymbol{B}=$ $B^{R 9}$.

a)

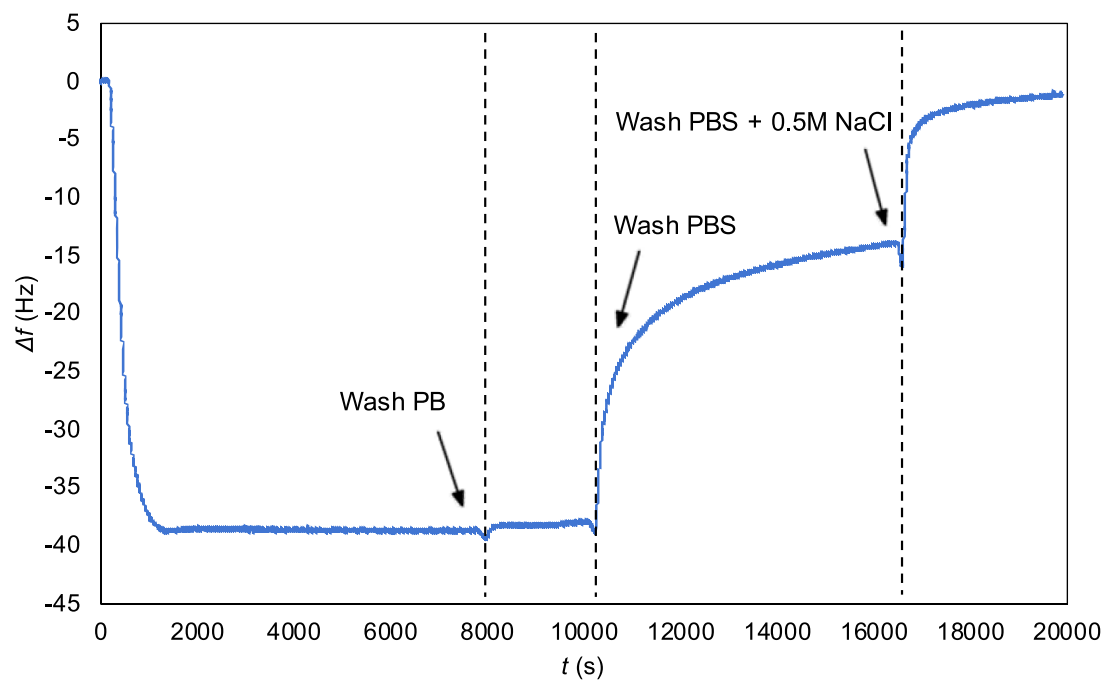

b)

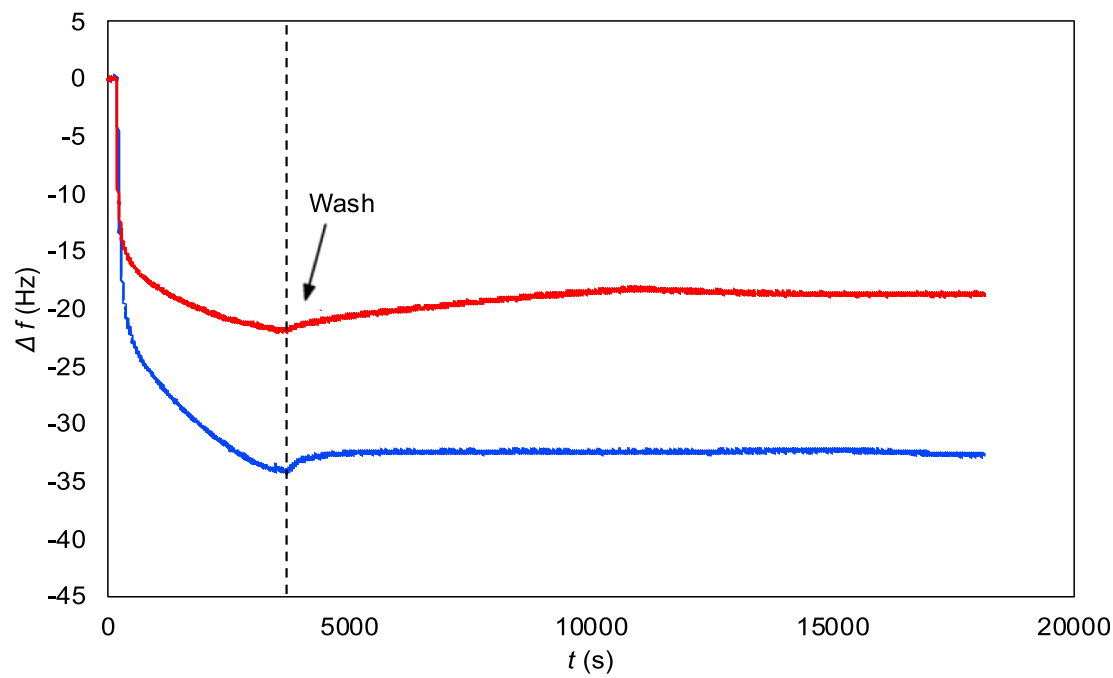

Figure 9. Salt-dependence of brush formation for $5 \mu \mathrm{M} B^{R T}-E_{40}^{S}$. Frequency shift $\Delta f$ vs time $t$. (a) Adsorption of $B^{R T}-E_{40}^{S}$ from PB followed by washing with $\mathrm{PBS}(150 \mathrm{mM} \mathrm{NaCl})$, followed by washing with a high salt buffer (PBS $+0.5 \mathrm{M} \mathrm{NaCl})$. (b) Adsorption from PB followed by washing with PB (blue), compared with adsorption from PBS followed by washing with PBS (red). 


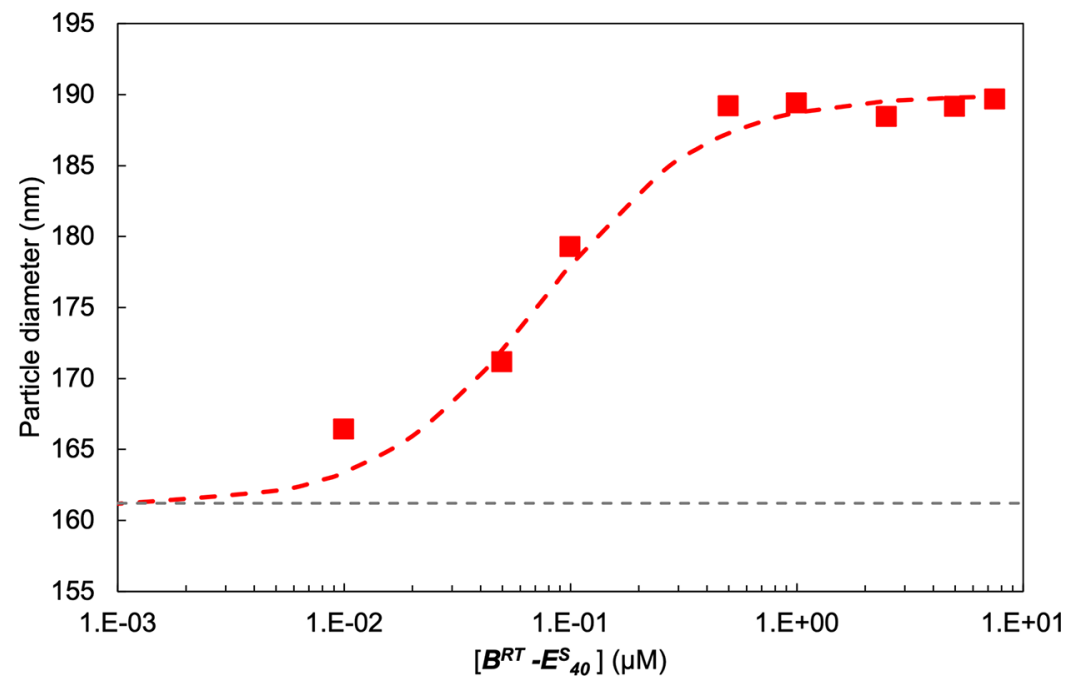

Figure 10. Formation of stable polymer brush on silica particles measured with DLS. Particle diameter vs concentration of $B^{R T}-E^{S}{ }_{40}$. Bare nonporous silica particles were incubated with increasing concentrations of $B^{R T}-E_{40}^{S}$ and the particle size was measured by means of DLS. Each measurement was repeated three times, error bars are contained within the size of the dot. The gray-dashed line represents the measured hydrodynamic diameter of bare silica particles.
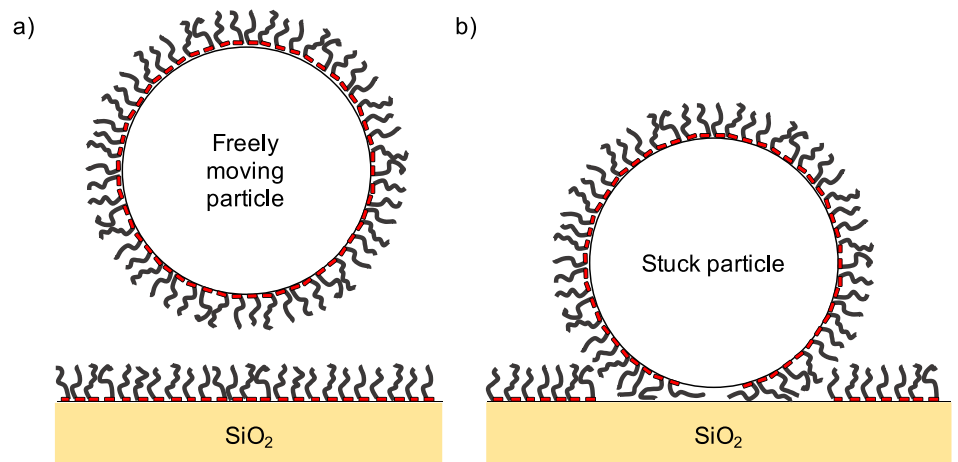

c)

Figure 11. Schematic representation of the particle mobility assay. Particles coated with biomolecules such as ssDNA, streptavidin, and $\boldsymbol{B}^{R T}-\boldsymbol{E}_{40}^{\boldsymbol{S}}$ sediment to the surface of the substrate and show Brownian motion. The mobility and fraction of stuck particles is influenced by the interactions between particles and surfaces. (a,b) Schematic of a particle not interacting with the surface and a particle strongly interacting. (c) Example of particle position trajectories recorded over time for multiple particles. The insets show typical observed trajectories for a stuck and freely moving particle.

concentrations of the diblock polypeptide $B^{R T}-E_{40}^{S}$. As shown in Figure 10, for the bare silica particles, a hydrodynamic diameter of $161 \pm 0.8 \mathrm{~nm}$ was determined, in agreement with the manufacturer specifications. Upon increasing the $B^{R T}-E_{40}^{S}$ diblock concentration, the particle diameter increases until it stabilizes at a final diameter of approximately $189 \mathrm{~nm}$ at 0.5 $\mu \mathrm{M} B^{R T}-E_{40}^{S}$. This implies an approximate hydrodynamic brush height of $h \approx 14 \mathrm{~nm}$. In a separate DLS experiment, it was found that the hydrodynamic diameter of the free $B^{R T}$ $\boldsymbol{E}_{40}^{S}$ diblock, which is dominated by the coil size of the $\boldsymbol{E}_{40}^{S}$ block, was $D_{\mathrm{H}}=9 \pm 1 \mathrm{~nm}$. This suggests that the $\boldsymbol{E}_{40}^{S}$ chains are somewhat stretched. A similar result was found for polypeptide brushes self-assembled around DNA. ${ }^{60}$

In searching for effective hydrophilic brush-forming polypeptides, we were motivated by a novel single-molecule biosensing platform in which the mobility of a functionalized micrometer-sized particle, tethered to a functionalized surface, is modulated by single-molecule interactions, as reported by some of us. ${ }^{61-63}$ This new biosensing platform allows for continuous monitoring of analytes and is based on affinity interactions, for example, an antibody sandwich or competition assay. For such a platform, it is essential to completely block interaction of the tethered particles with nonfunctionalized surfaces. As a first demonstration of the functionality of the self-assembled brushes in a biosensing application, we demonstrate the effectiveness of the $B^{R T}-E^{S}$ diblocks in blocking nonspecific particle-surface interactions. Note that for full functionality of the polypeptides in biosensing, we will also need to show adequate antifouling against smaller biomolecules and long-term stability of the brushes. This will be the subject of later studies.

Blocking of nonspecific interactions by polypeptide brushes formed by $B^{R T}-E_{40}^{S}$ diblocks on silica nanoparticles and glass slides was tested using a particle mobility assay, as illustrated in Figure 11. The interactions between particles and surface are directly reflected by the mobility. ${ }^{64}$ To record the mobility of micron-sized particles over time, we used dark-field microscopy. The position of every particle at each frame is localized with an accuracy of about $20 \mathrm{~nm}$ and then reconstructed into a trajectory over time. Silica particles and magnetic particles with specific modifications are sedimented onto the surface of coated glass slides and their trajectories are reconstructed. For 
each particle, a two-dimensional diffusion coefficient $D_{2 \mathrm{D}}$ is determined from the mean-squared displacement $\left\langle\left(r^{-}(t+\tau)\right.\right.$ $\left.\left.-r^{-}(t)\right)^{2}\right\rangle=4 D_{2 \mathrm{D}} \tau$. By analyzing the particle trajectories and setting a threshold for the diffusion coefficient, freely moving particles and stuck particles are distinguished and percentages are obtained for particles that ultimately become stuck. Results are given in Table 5, for various types of particles and for

Table 5. Fraction of Differently Modified Particles Stuck to Differently Modified Silica Surfaces (\%), as Obtained from a Particle Mobility Assay

\begin{tabular}{llc} 
& \multicolumn{2}{c}{ glass modification } \\
\cline { 2 - 3 } particle type, modification & $\boldsymbol{B}^{R T}-\boldsymbol{E}_{40}^{S}$ & PLL-g-PEG \\
silica, $\boldsymbol{B}^{R T}-\boldsymbol{E}_{40}^{S}$ & $1.3 \pm 0.6$ & $3.8 \pm 0.9$ \\
silica, PLL- $g$-PEG & $1.9 \pm 0.6$ & $2.5 \pm 0.2$ \\
polystyrene, ssDNA & $1.0 \pm 0.7$ & $25.0 \pm 14.6$ \\
polystyrene, biotin-PEG & $1.7 \pm 0.8$ & $12.6 \pm 6.0$ \\
polystyrene, streptavidin & $3.2 \pm 1.0$ & $80.1 \pm 13.0$ \\
\hline
\end{tabular}

particle and surface coatings with $B^{R T}-E_{40}^{S}$ diblock polypeptides and PLL-g-PEG copolymers, the current standard for self-assembled antifouling brushes. While both $B^{R T}-E_{40}^{S}$ and PLL- $g$-PEG coatings are effective in preventing nonspecific interactions if both the particle and the surface are nonfunctionalized, various functionalized particles with biosensing applications such as ssDNA-, biotin-PEG-, and streptavidincoated particles stick stronger to PLL-g-PEG-coated glass slides. In contrast, minimal nonspecific interactions are found between these functionalized particles and glass slides coated with $B^{R T}-E^{S}{ }_{40}$, demonstrating the usefulness of $B^{R T}-E^{S}{ }_{40}$ as a blocker of nonspecific particle-surface interactions.

\section{CONCLUDING REMARKS}

By comparing surface binding of different arginine-rich silicabinding peptides $\boldsymbol{B}$, we have established that in-plane, peptide-peptide interactions play a crucial role in the formation of adsorbed silica-binding peptide layers. Presumably thanks to the cooperative nature of the layer formation by the SBPs $\boldsymbol{B}$, the self-assembled brushes formed by the $\boldsymbol{B}-\boldsymbol{E}_{40}^{\boldsymbol{S}}$ diblocks are excellent blockers of various nonspecific interactions.

Possible advantages of these polypeptides over other selfassembling brush systems such as PLL-g-PEG are that the former can directly be used as recombinant silica-immobilization tags for functional proteins. Also, we have found that at least for some cases, such as in blocking nonspecific interactions of functionalized particles with glass surfaces, PLL- $g$-PEG does not perform as effectively as $B^{R T}-E_{40}^{S}$. Nonetheless, further testing is necessary to evaluate the antifouling properties of our polymer brush compared to PLL-g-PEG. Since binding peptides have been investigated for many types of surfaces, such as plastics, metals, and other oxides, the polypeptide approach also appears to be easier to generalize than the synthetic adsorbing bottle-brush systems.

These diblocks are also a good starting point for the design of polypeptides that form brushes with even better salt resistance, as may be required for some applications. Stronger attachment of the brushes to the silica could possibly be engineered by arranging for yet more binding cooperativity. For example, elaborating on a previous example of silicabinding ELP micelles, ${ }^{19}$ one could try designing triblock polypeptides featuring an additional "self-assembly" midblock, which could, for example, be a more hydrophobic ELP block. Alternatively, one could try to include multiple binding tags in a linear topology, although in this case, the gain in binding strength needs to be balanced against an inevitable reduction of the grafting density of the polymer brush.

\section{ASSOCIATED CONTENT}

\section{Supporting Information}

The Supporting Information is available free of charge at https://pubs.acs.org/doi/10.1021/acs.biomac.1c00067.

Sequences of synthetic genes for diblock expression, amino acid sequence of diblock polypeptides, QCM-D data for SBPs $B^{R Q}$ and $B^{R 14}$, AFM images of SBPs $B^{R T}$, $B^{R Q}$, and $B^{R 14}$, schematic and data analysis of singlemolecule AFM-based force spectroscopy for SBPs $B^{R Q}$ and $B^{R 13} C y s$, and event selection for measurement of force-extension curves using AFM (PDF)

\section{AUTHOR INFORMATION}

\section{Corresponding Author}

Renko de Vries - Physical Chemistry and Soft Matter, Wageningen University and Research, Wageningen 6708 WE,

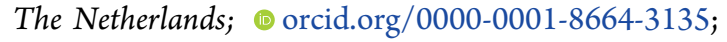
Email: renko.devries@wur.nl

\section{Authors}

Nicolò Alvisi - Physical Chemistry and Soft Matter, Wageningen University and Research, Wageningen 6708 WE, The Netherlands; 10 orcid.org/0000-0003-0378-3234

Fabiola A. Gutiérrez-Mejía - Physical Chemistry and Soft Matter, Wageningen University and Research, Wageningen 6708 WE, The Netherlands

Meike Lokker - Physical Chemistry and Soft Matter, Wageningen University and Research, Wageningen 6708 WE, The Netherlands

Yu-Ting Lin - Department of Applied Physics and Institute for Complex Molecular Systems (ICMS), Eindhoven University of Technology, Eindhoven 5600 MB, The Netherlands

Arthur M. de Jong - Department of Applied Physics and Institute for Complex Molecular Systems (ICMS), Eindhoven University of Technology, Eindhoven $5600 \mathrm{MB}$, The

Netherlands; (1) orcid.org/0000-0001-6019-7333

Floris van Delft - Laboratory of Organic Chemistry, Wageningen University and Research, Wageningen $6708 \mathrm{WE}$, The Netherlands

Complete contact information is available at:

https://pubs.acs.org/10.1021/acs.biomac.1c00067

\section{Author Contributions}

N.A. and F.A.G.-M. contributed equally. The manuscript was written through contributions of all authors. All authors have given approval to the final version of the manuscript.

\section{Funding}

F.A.G.-M. was funded by the Industrial Partnership Programme "Designed hybrid networks using protein-like block copolymers" as a part of the agreement between Unilever Research and Development B.V. and The Netherlands Organisation for Scientific Research (NWO) with project number 15HSM10. N.A. and Y.-T.L. were funded by NWOTTW-OTP project number 15481.

\section{Notes}

The authors declare no competing financial interest. 


\section{REFERENCES}

(1) Sapsford, K. E.; Algar, W. R.; Berti, L.; Gemmill, K. B.; Casey, B. J.; Oh, E.; Stewart, M. H.; Medintz, I. L. Functionalizing Nanoparticles with Biological Molecules: Developing Chemistries That Facilitate Nanotechnology. Chem. Rev. 2013, 113, 1904-2074.

(2) Vogler, E. A. Protein Adsorption in Three Dimensions. Biomaterials 2012, 33, 1201-1237.

(3) Rabe, M.; Verdes, D.; Seeger, S. Understanding Protein Adsorption Phenomena at Solid Surfaces. Adv. Colloid Interface Sci. 2011, 162, 87-106.

(4) Saha, B.; Songe, P.; Evers, T. H.; Prins, M. W. J. The Influence of Covalent Immobilization Conditions on Antibody Accessibility on Nanoparticles. Analyst 2017, 142, 4247-4256.

(5) Yu, Q.; Zhang, Y.; Wang, H.; Brash, J.; Chen, H. Anti-Fouling Bioactive Surfaces. Acta Biomater. 2011, 7, 1550-1557.

(6) Lowe, S.; O’Brien-Simpson, N. M.; Connal, L. A. Antibiofouling Polymer Interfaces: Poly(Ethylene Glycol) and Other Promising Candidates. Polym. Chem. 2015, 6, 198-212.

(7) Baggerman, J.; Smulders, M. M. J.; Zuilhof, H. Romantic Surfaces: A Systematic Overview of Stable, Biospecific, and Antifouling Zwitterionic Surfaces. Langmuir 2019, 35, 1072-1084.

(8) Gon, S.; Fang, B.; Santore, M. M. Interaction of Cationic Proteins and Polypeptides with Biocompatible Cationically-Anchored PEG Brushes. Macromolecules 2011, 44, 8161-8168.

(9) Zhang, L.; Klein, B. D.; Metcalf, C. S.; Smith, M. D.; McDougle, D. R.; Lee, H.-K.; White, H. S.; Bulaj, G. Incorporation of Monodisperse Oligoethyleneglycol Amino Acids into Anticonvulsant Analogues of Galanin and Neuropeptide y Provides Peripherally Acting Analgesics. Mol. Pharm. 2013, 10, 574-585.

(10) Ding, Y.; Zhang, P.; Tang, X.-Y.; Zhang, C.; Ding, S.; Ye, H.; Ding, Q.-L.; Shen, W.-B.; Ping, Q.-N. PEG Prodrug of Gambogic Acid: Amino Acid and Dipeptide Spacer Effects. Polymer 2012, 53, 1694-1702.

(11) Saxer, S.; Portmann, C.; Tosatti, S.; Gademann, K.; Zürcher, S.; Textor, M. Surface Assembly of Catechol-Functionalized Poly(LLysine)- Graftpoly(Ethylene Glycol) Copolymer on Titanium Exploiting Combined Electrostatically Driven Self-Organization and Biomimetic Strong Adhesion. Macromolecules 2010, 43, 1050-1060.

(12) Urry, D. W. Physical Chemistry of Biological Free Energy Transduction as Demonstrated by Elastic Protein-Based Polymers. J. Phys. Chem. B 1997, 101, 11007-11028.

(13) Hassouneh, W.; MacEwan, S. R.; Chilkoti, A. Fusions of Elastin-like Polypeptides to Pharmaceutical Proteins. Methods Enzymol. 2012, 502, 215-237.

(14) Tang, Z.; Palafox-Hernandez, J. P.; Law, W.-C.; Hughes, Z. E.; Swihart, M. T.; Prasad, P. N.; Knecht, M. R.; Walsh, T. R. Biomolecular Recognition Principles for Bionanocombinatorics: An Integrated Approach to Elucidate Enthalpic and Entropic Factors. ACS Nano 2013, 7, 9632-9646.

(15) Sengupta, A.; Thai, C. K.; Sastry, M. S. R.; Matthaei, J. F.; Schwartz, D. T.; Davis, E. J.; Baneyx, F. A Genetic Approach for Controlling the Binding and Orientation of Proteins on Nanoparticles. Langmuir 2008, 24, 2000-2008.

(16) Care, A.; Bergquist, P. L.; Sunna, A. Solid-Binding Peptides: Smart Tools for Nanobiotechnology. Trends Biotechnol. 2015, 33, 259-268.

(17) Care, A.; Petroll, K.; Gibson, E. S. Y.; Bergquist, P. L.; Sunna, A. Solid-Binding Peptides for Immobilisation of Thermostable Enzymes to Hydrolyse Biomass Polysaccharides. Biotechnol. Biofuels 2017, 10, $1-16$.

(18) Wong Po Foo, C.; Patwardhan, S. V.; Belton, D. J.; Kitchel, B.; Anastasiades, D.; Huang, J.; Naik, R. R.; Perry, C. C.; Kaplan, D. L. Novel Nanocomposites from Spider Silk-Silica Fusion (Chimeric) Proteins. Proc. Natl. Acad. Sci. U.S.A. 2006, 103, 9428-9433.

(19) Li, L.; Li, N. K.; Tu, Q.; Im, O.; Mo, C.-K.; Han, W.; Fuss, W. H.; Carroll, N. J.; Chilkoti, A.; Yingling, Y. G.; et al. Functional Modification of Silica through Enhanced Adsorption of Elastin-Like Polypeptide Block Copolymers. Biomacromolecules 2018, 19, 298306.
(20) Li, L.; Mo, C.-K.; Chilkoti, A.; Lopez, G. P.; Carroll, N. J. Creating Cellular Patterns Using Genetically Engineered, Gold- and Cell-Binding Polypeptides. Biointerphases 2016, 11, 021009.

(21) Shah, M.; Hsueh, P.-Y.; Sun, G.; Chang, H. Y.; Janib, S. M.; MacKay, J. A. Biodegradation of Elastin-like Polypeptide Nanoparticles. Protein Sci. 2012, 21, 743-750.

(22) Van Eldijk, M. B.; McGann, C. L.; Kiick, K. L.; Van Hest, J. C. M. Elastomeric Polypeptides. Top. Curr. Chem. 2012, 310, 71-116.

(23) Li, L.; Shields, C. W.; Huang, J.; Zhang, Y.; Ohiri, K. A.; Yellen, B. B.; Chilkoti, A.; López, G. P. Rapid Capture of Biomolecules from Blood: Via Stimuli-Responsive Elastomeric Particles for Acoustofluidic Separation. Analyst 2020, 145, 8087-8096.

(24) Girotti, A.; Reguera, J.; Rodríguez-Cabello, J. C.; Arias, F. J.; Alonso, M.; Testera, A. M. Design and Bioproduction of a Recombinant Multi(Bio)Functional Elastin-like Protein Polymer Containing Cell Adhesion Sequences for Tissue Engineering Purposes. J. Mater. Sci.: Mater. Med. 2004, 15, 479-484.

(25) Zong, J.; Cobb, S. L.; Cameron, N. R. Short Elastin-like Peptide-Functionalized Gold Nanoparticles That Are Temperature Responsive under near-Physiological Conditions. J. Mater. Chem. B 2018, 6, 6667-6674.

(26) Shi, P.; Aluri, S.; Lin, Y.-A.; Shah, M.; Edman, M.; Dhandhukia, J.; Cui, H.; MacKay, J. A. Elastin-Based Protein Polymer Nanoparticles Carrying Drug at Both Corona and Core Suppress Tumor Growth in Vivo. J. Controlled Release 2013, 171, 330-338.

(27) Han, W.; MacEwan, S. R.; Chilkoti, A.; López, G. P. BioInspired Synthesis of Hybrid Silica Nanoparticles Templated from Elastin-like Polypeptide Micelles. Nanoscale 2015, 7, 12038-12044.

(28) Lee, J.; Kim, O.; Jung, J.; Na, K.; Heo, P.; Hyun, J. Simple Fabrication of a Smart Microarray of Polystyrene Microbeads for Immunoassay. Colloids Surf., B 2009, 72, 173-180.

(29) Lee, J.; Jung, J.; Na, K.; Heo, P.; Hyun, J. Polypeptide-Mediated Switchable Microarray of Bacteria. ACS Appl. Mater. Interfaces 2009, 1, 1359-1363.

(30) Hernandez-Garcia, A.; Werten, M. W. T.; Stuart, M. C.; De Wolf, F. A.; De Vries, R. Coating of Single DNA Molecules by Genetically Engineered Protein Diblock Copolymers. Small 2012, 8, 3491-3501.

(31) Zheng, T.; Perona Martínez, F.; Storm, I. M.; Rombouts, W.; Sprakel, J.; Schirhagl, R.; De Vries, R. Recombinant Protein Polymers for Colloidal Stabilization and Improvement of Cellular Uptake of Diamond Nanosensors. Anal. Chem. 2017, 89, 12812-12820.

(32) Thyparambil, A. A.; Wei, Y.; Latour, R. A. Determination of Peptide - Surface Adsorption Free Energy for Material Surfaces Not Conducive to SPR or QCM Using AFM. Langmuir 2012, 28, 56875694.

(33) Kim, S.-O.; Jackman, J. A.; Mochizuki, M.; Yoon, B. K.; Hayashi, T.; Cho, N.-J. Correlating Single-Molecule and EnsembleAverage Measurements of Peptide Adsorption onto Different Inorganic Materials. Phys. Chem. Chem. Phys. 2016, 18, 14454-14459.

(34) Krysiak, S.; Liese, S.; Netz, R. R.; Hugel, T. Peptide Desorption Kinetics from Single Molecule Force Spectroscopy Studies. J. Am. Chem. Soc. 2014, 136, 688-697.

(35) Tamerler, C.; Oren, E. E.; Duman, M.; Venkatasubramanian, E.; Sarikaya, M. Adsorption Kinetics of an Engineered Gold Binding Peptide by Surface Plasmon Resonance Spectroscopy and a Quartz Crystal Microbalance. Langmuir 2006, 22, 7712-7718.

(36) Ebner, A.; Wildling, L.; Gruber, H. J. Functionalization of AFM Tips and Supports for Molecular Recognition Force Spectroscopy and Recognition Imaging. Methods in Molecular Biology; Humana Press: New York, NY, 2019; Vol. 1886, pp 117-151.

(37) Oesterhelt, F.; Rief, M.; Gaub, H. E. Single Molecule Force Spectroscopy by AFM Indicates Helical Structure of Poly(EthyleneGlycol) in Water. New J. Phys. 1999, 1, 6.

(38) Friddle, R. W.; Noy, A.; De Yoreo, J. J. Interpreting the Widespread Nonlinear Force Spectra of Intermolecular Bonds. Proc. Natl. Acad. Sci. U.S.A. 2012, 109, 13573-13578. 
(39) Manohar, S.; Jagota, A. Sequence-Dependent Force Response during Peeling of Single-Stranded DNA from Graphite. Phys. Rev. E: Stat., Nonlinear, Soft Matter Phys. 2010, 81, 021805.

(40) Tang, N. C.; Chilkoti, A. Combinatorial Codon Scrambling Enables Scalable Gene Synthesis and Amplification of Repetitive Proteins. Nat. Mater. 2016, 15, 419-424.

(41) McDaniel, J. R.; MacKay, J. A.; Quiroz, F. G.; Chilkoti, A. Recursive Directional Ligation by Plasmid Reconstruction Allows Rapid and Seamless Cloning of Oligomeric Genes. Biomacromolecules 2010, 11, 944-952.

(42) Iler, R. K. The Chemistry of Silica: Solubility, Polymerization, Colloid and Surface Properties and Biochemistry of Silica; Wiley, 1979.

(43) Abdelhamid, M. A. A.; Ikeda, T.; Motomura, K.; Tanaka, T.; Ishida, T.; Hirota, R.; Kuroda, A. Application of Volcanic Ash Particles for Protein Affinity Purification with a Minimized SilicaBinding Tag. J. Biosci. Bioeng. 2016, 122, 633-638.

(44) Hassert, R.; Pagel, M.; Ming, Z.; Häupl, T.; Abel, B.; Braun, K.; Wiessler, M.; Beck-Sickinger, A. G. Biocompatible Silicon Surfaces through Orthogonal Click Chemistries and a High Affinity Silicon Oxide Binding Peptide. Bioconjugate Chem. 2012, 23, 2129-2137.

(45) Gladytz, A.; John, T.; Gladytz, T.; Hassert, R.; Pagel, M.; Risselada, H. J.; Naumov, S.; Beck-Sickinger, A. G.; Abel, B.; Friesner, R. A.; et al. Peptides@mica: From Affinity to Adhesion Mechanism. Phys. Chem. Chem. Phys. 2016, 18, 23516-23527.

(46) Thai, C. K.; Dai, H.; Sastry, M. S. R.; Sarikaya, M.; Schwartz, D. T.; Baneyx, F. o. Identification and Characterization of $\mathrm{Cu} 2 \mathrm{O}-$ and ZnO-Binding Polypeptides by Escherichia Coli Cell Surface Display: Toward an Understanding of Metal Oxide Binding. Biotechnol. Bioeng. 2004, 87, 129-137.

(47) Zernia, S.; Frank, R.; Weiße, R. H.-J.; Jahnke, H.-G.; BellmannSickert, K.; Prager, A.; Abel, B.; Sträter, N.; Robitzki, A.; BeckSickinger, A. G. Surface-Binding Peptide Facilitates Electricity-Driven NADPH-Free Cytochrome P450 Catalysis. ChemCatChem 2018, 10, $525-530$.

(48) Malmsten, M.; Linse, P.; Cosgrove, T. Adsorption of PEOPPO-PEO Block Copolymers at Silica. Macromolecules 1992, 25, 2474-2481.

(49) Hnilova, M.; So, C. R.; Oren, E. E.; Wilson, B. R.; Kacar, T.; Tamerler, C.; Sarikaya, M. Peptide-Directed Co-Assembly of Nanoprobes on Multimaterial Patterned Solid Surfaces. Soft Matter 2012, 8, 4327-4334.

(50) Rimola, A.; Sodupe, M.; Ugliengo, P. Affinity Scale for the Interaction of Amino Acids with Silica Surfaces. J. Phys. Chem. C 2009, 113, 5741-5750.

(51) Meißner, R. H.; Wei, G.; Ciacchi, L. C. Estimation of the Free Energy of Adsorption of a Polypeptide on Amorphous $\mathrm{SiO} 2$ from Molecular Dynamics Simulations and Force Spectroscopy Experiments. Soft Matter 2015, 11, 6254-6265.

(52) Friddle, R. W.; Battle, K.; Trubetskoy, V.; Tao, J.; Salter, E. A.; Moradian-Oldak, J.; De Yoreo, J. J.; Wierzbicki, A. Single-Molecule Determination of the Face-Specific Adsorption of Amelogenin's CTerminus on Hydroxyapatite. Angew. Chem., Int. Ed. 2011, 50, 75417545.

(53) Reiter-Scherer, V.; Cuellar-Camacho, J. L.; Bhatia, S.; Haag, R.; Herrmann, A.; Lauster, D.; Rabe, J. P. Force Spectroscopy Shows Dynamic Binding of Influenza Hemagglutinin and Neuraminidase to Sialic Acid. Biophys. J. 2019, 116, 1037-1048.

(54) Pfreundschuh, M.; Alsteens, D.; Wieneke, R.; Zhang, C.; Coughlin, S. R.; Tampé, R.; Kobilka, B. K.; Müller, D. J. Identifying and Quantifying Two Ligand-Binding Sites While Imaging Native Human Membrane Receptors by AFM. Nat. Commun. 2015, 6, 8857.

(55) Sand, K. K.; Friddle, R. W.; Deyoreo, J. J. Quantifying the Free Energy Landscape between Polymers and Minerals. Sci. Rep. 2017, 7, 8663.

(56) Tao, J.; Battle, K. C.; Pan, H.; Salter, E. A.; Chien, Y.-C.; Wierzbicki, A.; De Yoreo, J. J. Energetic Basis for the Molecular-Scale Organization of Bone. Proc. Natl. Acad. Sci. U.S.A. 2015, 112, 326331.
(57) Willems, L.; Van Westerveld, L.; Roberts, S.; Weitzhandler, I.; Calcines Cruz, C.; Hernandez-Garcia, A.; Chilkoti, A.; Mastrobattista, E.; Van Der Oost, J.; De Vries, R. Nature of Amorphous Hydrophilic Block Affects Self-Assembly of an Artificial Viral Coat Polypeptide. Biomacromolecules 2019, 20, 3641-3647.

(58) Willems, L.; Roberts, S.; Weitzhandler, I.; Chilkoti, A.; Mastrobattista, E.; Van Der Oost, J.; De Vries, R. Inducible Fibril Formation of Silk-Elastin Diblocks. ACS Omega 2019, 4, 9135-9143.

(59) Reviakine, I.; Johannsmann, D.; Richter, R. P. Hearing What You Cannot See and Visualizing What You Hear: Interpreting Quartz Crystal Microbalance Data from Solvated Interfaces. Anal. Chem. 2011, 83, 8838-8848.

(60) Storm, I. M.; Kornreich, M.; Hernandez-Garcia, A.; Voets, I. K.; Beck, R.; Cohen Stuart, M. A.; Leermakers, F. A. M.; De Vries, R Liquid Crystals of Self-Assembled DNA Bottlebrushes. J. Phys. Chem. B 2015, 119, 4084-4092.

(61) Visser, E. W. A.; Yan, J.; Van IJzendoorn, L. J.; Prins, M. W. J. Continuous Biomarker Monitoring by Particle Mobility Sensing with Single Molecule Resolution. Nat. Commun. 2018, 9, 1-10.

(62) Lubken, R. M.; De Jong, A. M.; Prins, M. W. J. Multiplexed Continuous Biosensing by Single-Molecule Encoded Nanoswitches. Nano Lett. 2020, 20, 2296-2302.

(63) Yan, J.; Van Smeden, L.; Merkx, M.; Zijlstra, P.; Prins, M. W. J. Continuous Small-Molecule Monitoring with a Digital Single-Particle Switch. ACS Sens. 2020, 5, 1168-1176.

(64) Yanagishima, T.; Di Michele, L.; Kotar, J.; Eiser, E. Diffusive Behaviour of PLL-PEG Coated Colloids on $\lambda$-DNA Brushes - Tuning Hydrophobicity. Soft Matter 2012, 8, 6792-6798. 